\title{
RESEARCH OPPORTUNITIES TO IMPROVE DSM IMPACT ESTIMATES
}

Prepared for the

\section{CALIFORNIA INSTITUTE FOR ENERGY EFFICIENCY}

\author{
Harry Misuriello, Mary Ellen F. Hopkins \\ The Fleming Group \\ Washington, D.C.
}

March 1992

This document was prepared with funding provided by the California Institute for Energy Efficiency's sponsors (including California electric and gas utilities), with additional support from the United States Department of Energy, and with guidance from the California Energy Commission, the California Public Utilities Commission, and The Regents of the University of California. All work performed at Lawrence Berkeley Laboratory is sponsored in part by the United States Department of Energy and is in accordance with Contract No. DE-AC0376 SF00098.

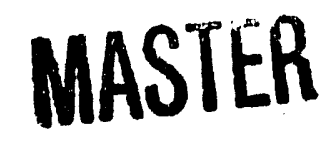




\section{TABLE OF CONTENTS}

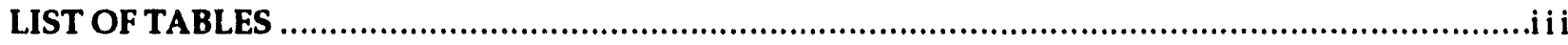

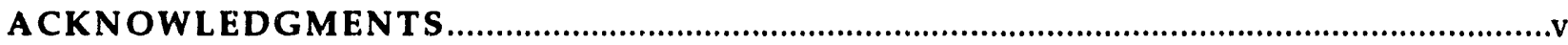

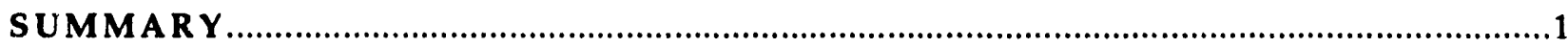

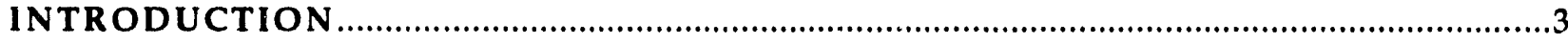

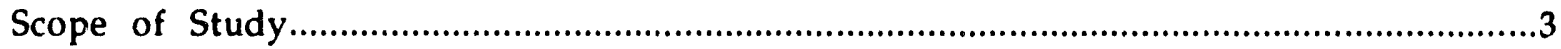

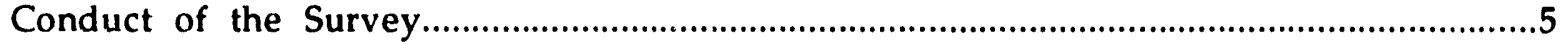

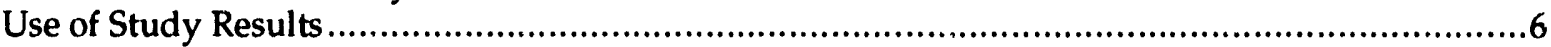

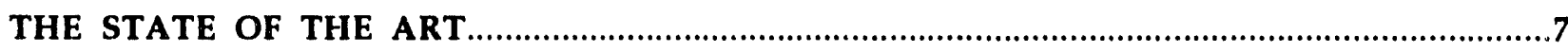

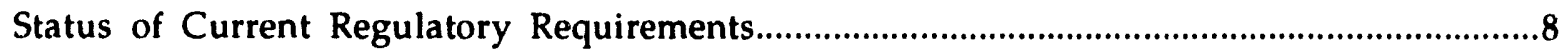

Impact-Evaluation Capabilities Issues..................................................................... 10

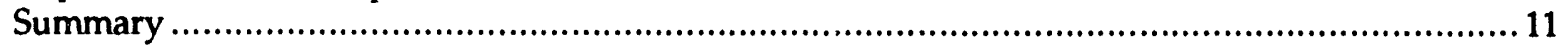

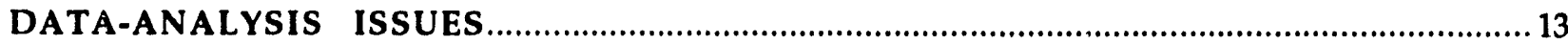

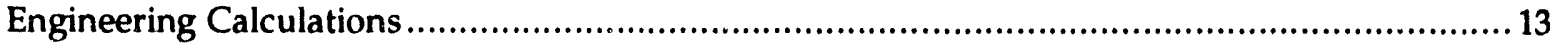

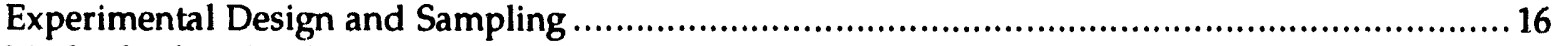

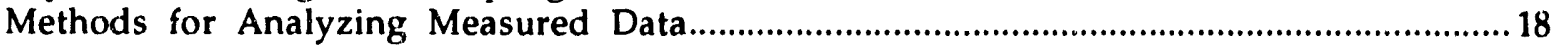

Use of Whole-Building Data for Impact Evaluation.................................................................. 19

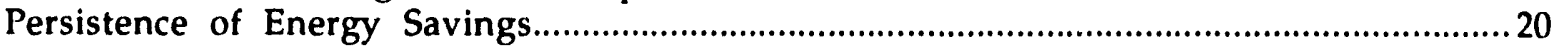

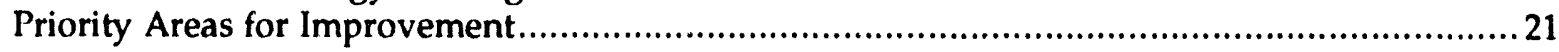

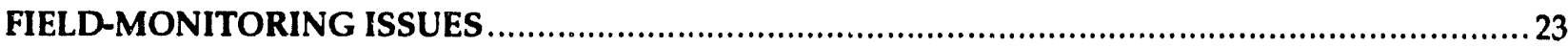

Role of Field Monitoring in DSM Impact Evaluation............................................................. 23

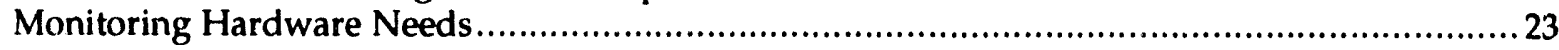

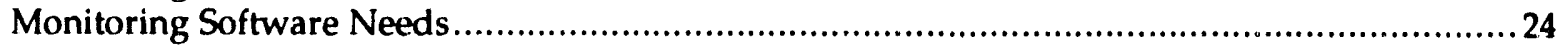

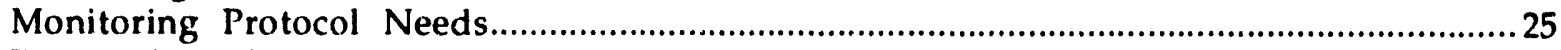

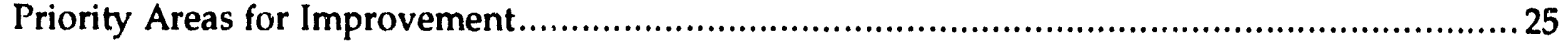

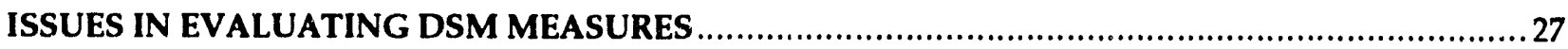

Problems and Issues with Evaluating HVAC Measures .............................................. 28

Problems and Issues with Evaluating Other DSM Measures ...........................................29

Priority Areas for Improvement.......................................................................... 29 
RECOMMENDATIONS FOR R\&D OPPORTUNITIES ........................................................

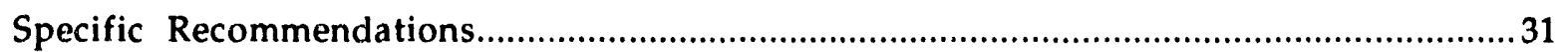

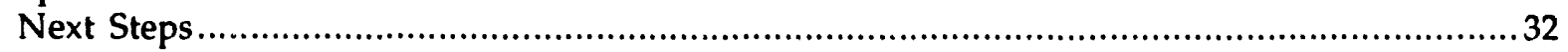

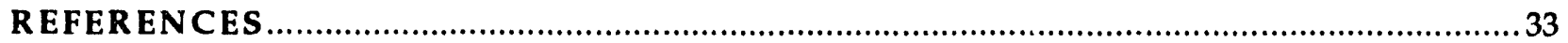

\section{APPENDICES}

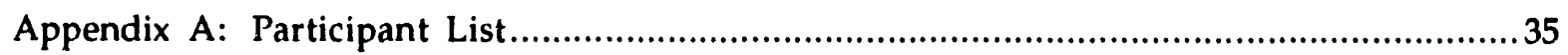

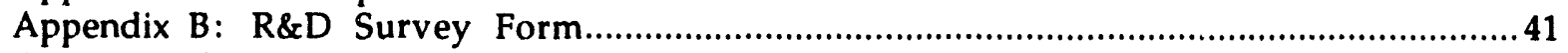

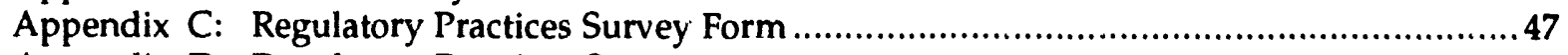

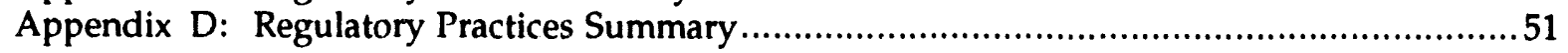




\section{LIST OF TABLES}

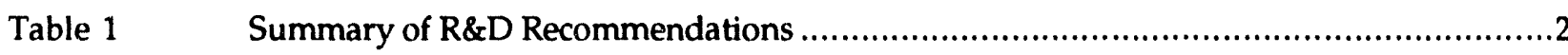

Table 2 Residential Savings (kWh Savings by End-Use/Measure) ..................................4

Table $3 \quad$ Nonresidential Savings (kWh Savings by End-Use Across All Sectors) ......................5

Table 4 Recommendations /Requirements for DSM Programs' Impact Evaluations ...................9

Table 5 Techniques Used in Preparing DSM Impact Evaluations.............................................9

Table 6 Improvements Recommended by Regulators ............................................... 10

Table D-1 Status of Regulatory Requirements for DSM Program Impact Evaluation...................52 


\section{ACKNOWLEDGMENTS}

This report was prepared by the Washington, D.C., office of The Fleming Group. Harry Misuriello was the Principal Investigator. Mary Ellen F. Hopkins was responsible for the regulatory practices survey. Maureen Higgins served as research assistant.

We wish to thank a number of people who provided invaluable assistance in this effort. Jim Cole, Director of the California Institute for Energy Efficiency (CIEE), provided policy direction and encouragement throughout the project. Ed Vine, CIEE Project Manager for the EndUse Resource Planning program, served as Technical Liaison and provided thoughtful feedback on our work. We also thank participants in the California Utility Research Council Semi-Annual Forum who reviewed our early results.

Most of all, we extend our thanks to our DSM evaluation colleagues and regulatory commission staff who gave so generously of their time and experience for our surveys.

Our acknowledgement of these individuals does not imply that they, or their organizations, agree with our conclusions or support our research recommendations. 
This report was commissioned by the California Institute for Energy Efficiency (CIEE) as part of its research mission to advance the energy efficiency and productivity of all end-use sectors in California.

Our specific goal in this effort has been to identify viable research and development (R\&D) opportunities that can improve capabilities to determine the energy-use and demand reductions achieved through demand-side management (DSM) programs and measures.

We surveyed numerous practitioners in California and elsewhere to identify the major obstacles to effective impact evaluation, drawing on their collective experience. As a separate effort, we have also profiled the status of regulatory practices in leading states with respect to DSM impact evaluation. We have synthesized this information, adding our own perspective and experience to those of our surveyrespondent colleagues, to characterize today's state of the art in impact-evaluation practices.

This scoping study takes a comprehensive look at the problems and issues involved in DSM impact estimates at the customer-facility or site level. The major portion of our study investigates three broad topic areas of interest to CIEE:

1. Data analysis issues: These include engineering calculations and other methods used to estimate DSM impacts; methods for analyzing measured energy performance data; experimental design and sampling; and persistence of energy savings.

2. Field-monitoring issues: These include innovations in metering and field-measurement technologies and ways to reduce the cost of field measurement.
3. Issues in evaluating DSM measures: These include technical and behavioral factors that are difficult to assess for specific DSM measures.

Across these three topic areas, we have identified 22 potential $R \& D$ opportunities, to which we have assigned priority levels. These $R \& D$ recommendations are listed in Table 1 . These $\mathrm{R} \& \mathrm{D}$ opportunities are listed by topic area and priority.

The results and recommendations of this, CIEE study are first and foremost intended tó identify priority R\&D opportunities to improve estimates of the energy and demand impacts of DSM measures. Viewed narrowly, hese R\&D opportunities could conceivably be restricted to the specific needs of California utilities and their implementation of DSM measurement plans. However, many of the shortcomings of DSM impact evaluation are common tć evaluation efforts nationwide. Cooperative research in these areas of recommended improvements is in the interest of the entire DSM community and should be pursued in that context. 
Table 1. Summary of R\&D Recommendations

\begin{tabular}{|c|c|c|}
\hline \multirow{10}{*}{$\begin{array}{l}\text { Priority } 1 \text { opportunities: } \\
\text { fill critical gaps to meet } \\
\text { basic evaluation } \\
\text { requirements }\end{array}$} & Analysis \#1 & Statewide DSM persistence study \\
\hline & Analysis \#2 & $\begin{array}{l}\text { Improvement of data and methods } \mathrm{fc} \text {. engineering } \\
\text { calculations }\end{array}$ \\
\hline & Analysis \#3 & Impact methods using whole-building techniques \\
\hline & Analysis \#4 & Short-term measurement techniques \\
\hline & Analysis \#5 & $\begin{array}{l}\text { Integration of statistical, engineering, and } \\
\text { behavioral models }\end{array}$ \\
\hline & Monitoring \#1 & Value-engineering study to reduce monitoring costs \\
\hline & Monitoring \#2 & Special "test kits" for DSM field measurement \\
\hline & Measures \#1 & Field-test methods for HVAC measures \\
\hline & Measures \#2 & Methods to evaluate low-impact measures \\
\hline & Measures \#3 & Methods to evaluate low-frequency measures \\
\hline \multirow{8}{*}{$\begin{array}{l}\text { Priority } 2 \text { opportunities: } \\
\text { new or advanced } \\
\text { methods to replace less } \\
\text { effective ones }\end{array}$} & Analysis \#1 & $\begin{array}{l}\text { Guidelines to calibrate simulation models with } \\
\text { measured data }\end{array}$ \\
\hline & Analysis \#2 & Literature guide to experimental design \\
\hline & Analysis \#3 & Statewide baseline performance data compilation \\
\hline & Analysis \#4 & $\begin{array}{l}\text { Reduction of multicollinearity through advanced } \\
\text { sampling techniques }\end{array}$ \\
\hline & Monitoring \#1 & $\begin{array}{l}\text { Expert-system applications for field-monitoring } \\
\text { projects }\end{array}$ \\
\hline & Monitoring \#2 & Site-measurement plan "recipe book" \\
\hline & Monitoring \#3 & Intrabuilding sampling techniques \\
\hline & Measures \#1 & Engineering field-test data for motors \\
\hline \multirow{4}{*}{$\begin{array}{l}\text { Priority } 3 \text { opportunities: } \\
\text { enhancements for existing } \\
\text { methods }\end{array}$} & Analysis \#1 & Protocols for data-collection project planning \\
\hline & Analysis \#2 & $\begin{array}{l}\text { Improvements to DSM administrative tracking } \\
\text { systems }\end{array}$ \\
\hline & Monitoring \#1 & Feasibility study on self-metering appliances \\
\hline & Measures \#1 & $\begin{array}{l}\text { Resolution of issues with interactive and secondary } \\
\text { effects }\end{array}$ \\
\hline
\end{tabular}


How much impact evaluation is enough? What are the major technical issues and problems with effective and accurate evaluation of DSM program impacts? What types of R\&D efforts are needed to overcome known shortcomings and advance the state of the art? These and other questions were put to a diverse group of DSM impact-evaluation practitioners in California and elsewhere around the country in an effort to characterize the current state of the art in this increasing!y important field and to identify specific R\&D opportunities in key technical areas.

Today these questions are particularly important in California, as they are in other states with large, aggressive DSM programs. Many utilities have chosen to rely on DSM as one means to meet future load growth; they look to impact measurement techniques to assess the reliability of DSM resources. In addition, California utilities are eligible for financial incentives for their DSM performance. In this context, impact-measurement techniques are integral to establishing the amount of incentives earned annually. California has recently reinvigorated its DSM efforts as part of its statewide collaborative process and has embarked on a three-year program to improve electric and gas utility methods to determine DSM load impacts. Toward this end, the Measurement Subcommittee of the California Collaborative has developed Measurement Protocols for DSM Programs Eligible for Shareholder Incentives (California Collaborative 1990) as a consensus guideline for the scope and detail to be addressed in individual utility impact-evaluation procedures. Approved utility applications for an incentive mechanism include a three-year measurement and evaluation plan to improve load-impact savings estimates. However, the Measurement
Subcommittee readily acknowledges that these procedures need considerable improvement.

CIEE has undertaken this scoping study as part of its mission to coordinate, plan, and implement a statewide program of medium- to longterm ( 5 to 15 years) applied research aimed at advancing the energy efficiency and productivity of all end-use sectors in California (CIEE 1991). The results and recommendations of this scoping study may lead to the initiation of research projects in CIEE's End-Use Resource Planning (ERP) program and to R\&D initiatives by other sponsors. One of the major goals of this program is to improve the ability of utilities to measure the energy and demand impacts that result from customer adoption of energy-efficient technologies. Within the ERP program are a number of topic areas of interest to CIEE. This scoping study is intended to identify viable $R \& D$ opportunities in the topic area of Technology Performance Analysis.

\section{SCOPE OF STUDY}

This effort focuses almost exclusively on measurement techniques and equipment used to determine how much DSM programs have reduced energy-use and demand in customer facilities. We emphasize site-level energy savings estimates as opposed to aggregate program-level savings achieved by a given population of DSM-program participants. Therefore, certain factors-such as free riders and transmission and distribution energy-loss adjustments (which figure into program-level estimates)are generally outside the scope of this effort. Nonetheless, this scoping study does take a comprehensive look at the problems and issues involved in DSM impact estimates at the customer-facility or site level. The major portion 
of the study investigates three broad topic areas of interest to CIEE:

1. Data-analysis issues: These include engineering calculations and other engineering methods (such as simulation models) used to estimate DSM impacts; methods for analyzing measured energy performance data; experimental design and sampling; and persistence of energy savings.

2. Field-monitoring issues: These include innovations in metering and field-measurement technologies that support wider use of these techniques for DSM impact measurement and innovations that can reduce the cost of field measurement. Processing of field-monitored data is also addressed.

3. Issues in evaluating DSM measures: These include technical and behavioral factors that are difficult to assess for specific DSM measures. Examples of these factors include actual, in-situ performance vs. rated or nameplate performance; interactive and secondary effects; actual vs. assumed operating hours; and thermostat control.
Evaluation of specific DSM measures is particularly important in California because the Collaborative's Measurement Protocols call for estimating five load-impact parameters for each measure included in a DSM program. These parameters are first-year (annual) energy savings, net-to-gross, rebound effect, useful life, and persistence. (A sixth parameter, loadshape impact, may be estimated at the end-use level instead of by DSM measure.)

For purposes of survey-form development for this topic area, we examined the types of DSM measures for which the three major investorowned California utilities reported savings in 1989 . We analyzed the annual utility DSM report for calendar year 1989 as specified in the California Public Utilities Commission's (CPUC's) Demand-Side Management Reporting Requirements Manual (CPUC 1990), focusing on reported first-year savings for residential and nonresidential programs and DSM measures. Tables 2 and 3 summarize aggregate savings by end-use across the three utilities.

The 1989 residential program data in Table 2 indicates that about $45 \%$ of reported savings is

Table 2. Residential Savings

( $k$ Wh Savings by End-Use/Measure)

\begin{tabular}{|l|c|c|}
\hline \hline End-Use/Measure & kWh Savings & $\%$ of Total \\
\hline \hline Refrigeration/freezer & $27,314,425$ & $22.7 \%$ \\
\hline Evaporative coolers & $26,063,800$ & $21.6 \%$ \\
\hline Lighting & $23,046,560$ & $19.1 \%$ \\
\hline Weatherization & $19,523,120$ & $16.2 \%$ \\
\hline Various & $15,688,182$ & $13.0 \%$ \\
\hline Air conditioning & $7,547,160$ & $6.3 \%$ \\
\hline Water heating & 690,900 & $0.6 \%$ \\
\hline Heat pumps ${ }^{*}$ TOTAL & $120,555,147$ & $0.6 \%$ \\
\hline \multicolumn{2}{|c|}{} & $100.0 \%$ \\
\hline \hline $\begin{array}{l}\text { HVAC-related measures account for } 44.6 \% \text { of total residential sav- } \\
\text { ings. }\end{array}$ \\
\hline
\end{tabular}


Table 3. Nonresidential Savings

(kWh Savings by End-Use Across all Sectors)

\begin{tabular}{|c|c|c|}
\hline End-Use & $\overline{\mathrm{kWh}}$ & $\%$ of Total \\
\hline Lighting & $147,661,680$ & $30.6 \%$ \\
\hline HVAC & $141,803,107$ & $29.4 \%$ \\
\hline Miscellaneous & $120,121,336$ & $24.9 \%$ \\
\hline Pumps & $22,900,973$ & $4.7 \%$ \\
\hline Refrigeration & $21,330,359$ & $4.4 \%$ \\
\hline Process & $17,178,101$ & $3.6 \%$ \\
\hline Water heating & $9,658,724$ & $2.0 \%$ \\
\hline Motors & $1,860,372$ & $0.4 \%$ \\
\hline TOTAL & $482,514,652$ & $100.0 \%$ \\
\hline
\end{tabular}

related to heating, ventilation, and air conditioning (HVAC), with nearly $22 \%$ of savings attributable to evaporative cooling measures. Refrigerator/freezer measures provide almost $23 \%$ of savings. Thirteen percent of residential savings are attributed to "various" measures. In the nonresidential sectors (commercial, industrial, and agricultural), lighting measures provide nearly $31 \%$ of savings, followed by HVAC measures $(29.4 \%)$ and "miscellaneous" measures $(25 \%)$.

Apart from their intended tracking purpose, this data is potentially useful for prioritizing impact-evaluation $R \& D$, especially where known evaluation shortcomings exist for DSM measures with significant reported savings. For example, as we discuss later on, survey respondents consistently identified HVAC measure evaluation as a priority problem area. However, this savings data should be examined annually to track the relative importance of problematic DSM measures.

Our study report also attempts to characterize the state of the art in DSM impact evaluation. As described in the next section of this report, we approached this objective from a number of perspectives. First, we asked the survey participants to identify projects that they would characterize as state of the art. Next, we surveyed public utility commissions (PUCs) on DSM impact requirements in states where least-cost utility planning procedur : and/or large-scale DSM efforts were in effect. PUC contacts were also asked to identify DSM impact evaluation shortcomings. Finally, we reviewed selected DSM impact literature sources.

\section{CONDUCT OF THE SURVEY}

The survey form shown in Appendix B was our primary data-collection instrument. The survey was administered by telephone in April and May 1991 to a diverse group of DSM impact practitioners in California and other states. The survey contacts shown in Appendix A represent a number of key groups: California utility $R \& D$ and measurement and evaluation (M\&E) staff, DSM consulting firms, research organizations, and measurement hardware manufacturers. The survey participants were generally responsible for planning and executing DSM evaluation projects. Most had been involved with conservation and DSM evaluations for some time (5 to 15 years), while others were relatively new to the field. Survey respondents were identified primarily through various conference author lists and CIEE sources.

The survey of state regulators was carried out in a parallel effort, using the telephone survey form shown in Appendix C. 


\section{USE OF STUDY RESULTS}

The results and recommendations of this CIEE study are first and foremost intended to identify priority R\&D opportunities to improve estimates of the energy and demand impacts of DSM measures. Viewed narrowly, these R\&D opportunities could conceivably be restricted to the specific needs of California utilities and their implementation of DSM measurement plans. However, many of the shortcomings of DSM impact evaluation are common to evaluation efforts nationwide. Indeed, some evaluation issues may only be resolved through cooperative efforts among a number of affected interests. For example, the issue of persistence of energy savings is critical to understanding the long-term reliability of DSM resources but may be beyond the resources of any one organization to resolve. We hope our $R \& D$ recommendations will attract the attention of organizations outside Califorria.

More specifically, CIEE intends to study these recommendations further and identify which $R \& D$ opportunities are appropriate in the context of its charter. CIEE will review these $R \& D$ recommendations with the California utilities and regulatory agencies before incorporating them into its research program. 
To provide some context for the results and recommendations we diccuss later on, this section is an overview of the state of the art in impact evaluation. This is mostly an exercise in judgment, because there are few benchmarks in this relatively new specialty field. Indeed, some observers have characterized DSM impact evaluation as still being in its infancy. However, we should make some distinctions in this characterization. Practitioners have been evaluating energy conservation and energyefficiency efforts for more than a decade. The waves of national and state energy-conservation legislation in the mid-1970s launched a number of major conservation efforts in such areas as institutional buildings, residential audits and conservation, low-income weatherization, and energy-efficiency standards for new buildings. Ultimately, these national programs were evaluated (with varying degrees of success) by building-energy researchers. In the early 1980s, large-scale regional conservation efforts, such as those sponsored by the Bonneville Power Administration (BPA), began to emerge. As these programs were evaluated, methodological advances were achieved. In retrospect, we believe these conservation programs established an evaluation infrastructure and laid the foundation for further advances in methodology. Hirst (1989) provides a historical perspective on these activities and charts the developments in evaluation methodologies.

Somewhat concurrent with these conservation efforts, the basic concepts of DSM for electric utilities were being developed in the early 1980s. However, the first wave of interest in DSM probably peaked in the mid-1980s, declining (along with general public interest in conservation) through the end of the Reagan administration. However, the relatively recent phenomenon of least-cost utility planning (or integrated resource planning) has reinvigorated
DSM activities nationwide. Funding levels for DSM have risen dramatically as DSM is considered, in principle, on an equal basis with traditional supply options. This new phase has raised new issues: environmental externalities, bidding, end-use fuel substitution, and utility performance incentives, to name a few. In this phase, impact evaluation has taken on a renewed urgency, largely influenced by regulatory concerns that DSM impacts are reliably forecast and of large magnitude. Thus we are observing the development of a modern DSM impact-evaluation field that tries to incorporate the best strengths of evaluation technique, engineering, and statistics. It is the state of this art that is our focus.

Until recently there has been no comprehensive guide to DSM impact-evaluation practices. However, the Electric Power Research Institute (EPRI) has begun to publish a handbook series on impact evaluation of DSM programs. The first volume in this series, $A$ Guide to Current Practice (EPRI 1991), is a landmark document that fills critical information gaps in this field. Comprehensive in scope, this document guides researchers through all aspects of impact evaluation, including detailed reviews of alternative quantitative methods. Unfortunately, distribution and use of this document are restricted by EPRI's licensing agreement. More accessible and traditional literature sources in this specialized field include the proceedings of the biennial Conference on Energy Program Evaluation. The fifth conference in this series was held in August 1991. Program-evaluation literature is also found in the proceedings of the biennial Summer Study on Energy Conservation in Buildings, sponsored by the American Council for an Energy-Efficient Economy (ACEEE). The five Summer Studies held since 1982 have published proceedings that treat program evaluation and performance 
measurement and analysis topics. The 1990 Summer Study features eight invited papers that review the state of the art in various energy-conservation topics. A number of these reviews address evaluation (ACEEE 1991). EPRI and other organizations sponsor the biennial National Conference on Utility DSM Programs. These proceedings also include program monitoring and evaluation topics. Finally, individual DSM practitioners formed the Association of Demand-Side Management Professionals (ADSMP) in 1989. ADSMP maintains an active Topic Committee on Program Evaluation and Monitoring, which seeks to keep its members up to date on all aspects of this quickly developing field.

This retrospeciive look at program evaiuation and overview of major literature sources helped us form opinions about the state of the art. However, we also examined the viewpoints and expectations of the utility regulators who have given policy and technical direction to the field. In addition, we reviewed our survey respondents' perspectives on issues that shape their practice.

\section{STATUS OF CURRENT REGULATORY REQUIREMENTS}

State regulatory agencies have been the driving force in DSM program planning, development, and evaluation as part of least-cost utility planning activities. We interviewed regulatory staff from the 19 states considered most active in least-cost planning activity to investigate the status of impact evaluation for DSM programs. Interviews were conducted in person and by telephone during March and April 1991. Respondents from each agency are responsible for review and evaluation of DSM program planning and evaluation of both electric and natural-gas utilities. All states in the survey have least-cost planning practices in effect for electric utilities, and nine of these have also recently become active in natural-gas DSM program development (Hopkins 1990). The 23 re- spondents answered 13 questions in three topic areas. The topic areas covered by the survey were regulatory practice, impact evaluation issues, and recommendations for improvement. A summary of each interview is included in Appendix D.

Seven of the 19 states in which we conducted interviews have formal requirernents in place for DSM program-impact evaluation. These states require DSM prograrn impact evaluation for all full-scale DSM programs and for most pilot programs. Of the 13 states without formal requirements, six include impact: evaluation in the customary review of DSM program plans or in rate cases. The remaining seven states recommend that impact evaluation be done for DSM programs, and several of these expect requirements in the near future. Af, shown in Table 4 , nearly all of the respondents indicated that their states have impact-evaluation requirements or recommendations in effect for DSM programs. Evaluation is most frequently recommended for full-scale and pilot electric DSM programs. Only three states indicated that they recommend a separate impact evaluation for energy audits or customer information programs. No explicit methodologies are set out by the regulators in any of the 19 states, although 10 states reported that evaluation guidelines (including objectives for evaluation) were available to utilities. Many state regulatory staff regularly advise vitilities on the best methods for perforning DSM impact evaluations.

Respondents were asked if a series of techniques commonly used in preparing DSM impact evaluations was used by utilities in their state and, if so, whether they considered these technologies satisfactory. As noted in Table 5, the most frequentiy cited technique is billing-data anal$y$ sis, used satisfactorily by utilities in 18 of the 19 states. The technique eliciting the most positive responses from regulators is end-use monitoring, in use by utilities in $\mathbf{1 5}$ of the states interviewed. Nearly all indicated that they wanted to see more end-use metering studies using well-designed control groups. The high cost of metering forces a trade-off between accuracy and expense for many utilities. The high cost of 
Table 4. Recommendations/Requirements for DSM Programs' Impact Evaluations (19 States Interviewed)

\begin{tabular}{|l|c|}
\hline Type of Program & Number of States \\
\hline Audit or information programs & 3 \\
\hline All full-scale DSM programs & 17 \\
\hline Pilot DSM programs & 17 \\
\hline Electric utility DSM programs only & 10 \\
\hline Electric and gas DSM programs & 9 \\
\hline
\end{tabular}

Table 5. Techniques Used in Preparing DSM Impact Evaluations

\begin{tabular}{||l|c|c|}
\hline \multirow{2}{*}{ Technique Used } & \multicolumn{2}{|c|}{ Number of States } \\
\cline { 2 - 3 } & Satisfactory & Unsatisfactory \\
\hline \hline Billing data analysis & 18 & \\
\hline Engineering estimates & 13 & 5 \\
\hline Statistical methods & 7 & \\
\hline End-use monitoring & 15 & \\
\hline Case studies of technology assessments & 9 & \\
\hline Hybrid methods & 13 & \\
\hline Savings estimates from other jurisdictions & 7 & 3 \\
\hline
\end{tabular}

monitoring has led to a call for evaluation studies that are transferable to other utilities in the state. Engineering estimates or calculations, including simulation models, are used in 18 of the 19 states but are considered unsatisfactory by regulators in five states. Critics of the engineering estimates complain that such estimates are better for DSM program design than for evaluation, and one commented that engineering estimates tend to overestimate conservation potential. The evaluation technique least popular with state commission staff is savings estimates from other jurisdictions; it is considered satisfactory by regulators only in the absence of more reliable data.

All respondents queried told us they expected the evaluation of DSM programs to improve. A majority of respondents, representing 15 of the 19 states, reported being dissatisfied with the quality and thoroughness of evaluation pro- grams to date. As noted in Table 6, regulators seek to raise the level of sophistication in DSM impact evaluation. Respondents from four of the states reported that they were beginning to develop evaluation plans but that it was too early to predict improvements. Regulators from 15 other states offered a variety of suggestions for improvements. All improvements would increase the accuracy and level of confidence in DSM evaluation and would increase accountability for DSM expenses. Several regulators cited the need for more professionally trained evaluators.

Clearly, DSM program evaluation is a growth activity in any state with least-cost planning. Nearly all regulators interviewed sought better DSM program design and implementation, more accurate results, and more DSM program evaluators. Regulators are calling for more investment in DSM program evaluation by 
Table 6. Improvements Recommended by Regulators

\begin{tabular}{|l|c|}
\hline Recommended Improvement & Number of States \\
\hline Too early to say & 4 \\
\hline Accuracy & 4 \\
\hline More end-use metering & 3 \\
\hline Replication/technology transfer & 2 \\
\hline $\begin{array}{l}\text { Better methods for process evaluation, planning, DSM } \\
\text { program development, and commercial/industrial } \\
\text { programs }\end{array}$ & 5 \\
\hline More trained evaluators & 4 \\
\hline
\end{tabular}

utilities and more attention from regulators. The issue is expected to become more important as incentives for conservation achievement are considered.

\section{IMPACT-EVALUATION CAPABILITIES ISSUES}

The work of evaluation practitioners is critically monitored by numerous parties. For example, utility regulators can impose demanding performance criteria, and results and methods must often be defended in public regulatory proceedings. Consumer and environmental advocates often have their own evaluation requirements and may participate in evaluation design and review of results through various collaborative processes. Utility management is also watching and tracking progress toward DSM goals and monitoring the achievement of performance incentives.

We asked our survey respondents to indicate how satisfied they were with their ability to meet these demands and to highlight significant problems. There was general agreement in the following areas:

- Accuracy of estimates: Some respondents felt that typical accuracy was in the range of $\pm 30 \%$ for impact estimates. However, they admitted that there was little hard information to support this statement. The accuracy of impact estimates is not well known. EPRI's Guide to Current Practice notes many uncertainties in these estimates and suggests an upper limit to precision of about $\pm 10 \%$.

- Pressure for single-point answers: Many practitioners insist that estimates of DSM impacts be reported as a range of possible answers and that independent results from two to three methods be used to check consistency. However, respondents report pressure to provide single-number results.

- Effect of performance incentives: Impact estimates are often used to determine utilities' monetary incentives for DSM performance. The respondents generally noted few adverse effects other than requirements for more detailed documentation of procedures. However, some volunteered that this extra scrutiny has made them more careful in carrying out evaluations.

- Skepticism toward statistical approaches: Some respondents were concerned that evaluations relied too heavily on statistical procedures such as conditional demand analysis and other regression techniques. They would have more faith in procedures based on end-use data. These proponents cited numerous confounding factors affecting DSM measures (including occupancy and equipment control) that may be detected only through this data. 
- Quality problems with basic data: Impact evaluation has significant data requirements such as customer characteristics, energy use data, and energy audit results. However, we heard many reports of problems with these basic parameters, such as customer information and billing systems not set up to facilitate use of this data, errors made on customer rebate forms, and onsite surveys containing errors in operating hours and installed-equipment capacities.

- Shortage of trained personnel: Respondents in California and elsewhere noted that the recent surge in evaluation activity necessitates staff expansion; however, the pool of trained evaluators is not perceived as large enough to meet the expanding demand. This suggests a need for training and educating entry-level personnel as well as for training personnel brought in from other fields. Universities may be able to develop an effective training and education curriculum combining appropriate elements of evaluation technique, engineering, statistics, and specialized DSM knowledge.

Overall, our respondents were satisfied that they were doing the best work they could given the current state of the practice and typical time and budget constraints. They acknowledged methodological shortcomings but anticipated improvements. Their main concern was inability to meet unrealistic expectations.

\section{SUMMARY}

Opinions about the state of the art of DSM impact evaluation vary. Utility regulators express dissatisfaction with the current level of evaluation plans, while practitioners are satisfied that they are doing the best they can. Regulators are uniformly confident of improvements in the general level of evaluation research as utilities invest more dollars in DSM programs and increasingly consider incentive awards for conservation achievement. Both parties are concerned with accuracy and confi- dence levels of results. Unfortunately, there may be no way to make an objective assessment.

However, years of hard-earned experience are reflected in the literature of this field, and the constant quest for improved methodologies shows commitment to excellence by both sponsors and practitioners. Thus, we should not lower our expectations that impact-evaluation practices will improve. 
The use of data-analysis methods for DSM impact evaluation is a broad topic and one in which numerous opportunities may exist for methodological improvements. However, not all impact-analysis methods are subject to significant problems. For example, some utilitybill analysis methods, such as PRISM for heating-energy savings, are reliable in certain applications (EPRI 1991). In structuring our survey questionnaire to address problems and issues in this area, we selected a number of subtopics in which we thought respondents would identify problem areas appropriate for $R \& D$ projects. The areas we decided to focus on are engineering calculations, experimental design and sampling, methods for extrapolating results, methods for processing and analyzing DSM impact data, use of whole-building data for impact evaluation, and persistence of energy savings.

\section{ENGINEERING CALCULATIONS}

Engineering calculations have always been integral to estimates of energy savings, not only for DSM measures and programs, but also for many energy conservation programs of long standing, such as the United States Department of Energy's (DOE's) Institutional Building Grant (or Schools and Hospitals) program. Engineering calculations are appealing because of their simplicity of use, their relatively low implementation cost, their flexibility in treating a wide range of DSM measures (and interactions between measures), and their inherent ability to be readily understood and interpreted by users and reviewers. Of course, engineering calculations by definition rely on simplifying assumptions of one type or another, and overall accuracy is limited by the accuracy of the assumptions used.
Today, engineering calculations of DSM savings are widely used to prepare forecasts of potential DSM impacts by customer sector as part of DSM program design, estimate DSM impacts and cost-effectiveness at individual customer facilities as part of a pre-retrofit energy audit, and estimate post-retrofit DSM impacts for program evaluation purposes. In the latter application, the results of engineering calculations (or the calculations themselves) are often incorporated into utility DSM administrative "tracking" systems, or databases. These systems typically report (among other things) DSM savings by program, customer sector, program participant, end-use, and measure.

\section{Types of Engineering Calculations}

Some of the common types of engineering calculations reported by our survey respondents include:

- Unit savings estimates: These estimates assign a precalculated value for energy savings to each DSM measure on a per-unit basis. For example, annual savings may be estimated for an energy-efficient refrigerator that replaces a conventional unit. This factor is then used to scale energy savings according to the number of units installed. This approach is a popular feature of DSM program tracking systems and has been applied to numerous DSM measures, such as compact fluorescent light bulbs, shower flow restrictors, and envelope improvements (wall and roof insulation and glazing on a square-foot basis). Unit savings estimates make the most use of simplifying assumptions because they typically do not account for site-specific variations that affect energy use and savings (such as hours of lighting use, family size as it affects shower use, and thermostat settings). 
- Engineering algorithms: Probably the most familiar type of engineering calculation, engineering algorithms attempt to account for site-specific factors in calculations of energy savings. For example, an engineering algorithm for lighting-energy savings usually takes into consideration such factors as actual reported hours of lighting use, existing installed lighting wattage, and installed lighting wattage after the retrofit. However, these factors are not usually measured in the field: lighting hours are often determined through occupant or building-operator interviews, and lighting wattage is determined by counting lighting fixtures and using rated nameplate data for bulb and ballast wattage. This data is often collected during relatively brief "walkthrough" building surveys that provide a snapshot of building operations at one point in time. Engineering algorithms for HVAC measures may use simplified data for weather inputs (heating degree days, for example) and space-conditioning equipment performance (such as COP, EER, and AFUE). These engineering algorithms are essentially hand calculations that rely heavily on data-input assumptions to estimate DSM measure savings.

- Simulation models: These estimating tools perform detailed computer simulations of annual whole-building energy use and use either hour-by-hour weather data (such as DOE-2) or temperature bin weather data (such as ASEAM). Input data for these models is typically comprehensive, taking into account all significant physical, operational, and equipment performance factors. Input data is developed from building blueprints and specifications as well as onsite inspections. Simulation models can be calibrated to actual energy-use records or data from on-site metering. DSM savings are determined by comparing modeled base case or pre-retrofit energy consumption to modeled post-retrofit energy use. Through proper sequencing of simulations, these models can be used to determine DSM savings by measure and to determine interactive effects between measures. As with engineering algorithms, the accuracy of simulation models is tied to the accuracy of input assumptions.

- Hybrid approaches: Some respondents reported using impact-analysis methods that combine engineering calculations or simulation models with some type of on-site monitoring activity. The goal of these approaches is to minimize the use of assumptions for critical engineeringcalculation parameters. For example, some lighting-retrofit evaluations have used short-term end-use metering to develop more realistic lighting use profiles and spot measurements to determine fixture-lighting wattage before and after the retrofit. These approaches are more fully discussed in the next chapter.

\section{Problems and Issues With Engineering Calculations}

Our survey respondents had no difficulty identifying and describing the shortcomings they perceived in engineering calculations. It is interesting to note that respondents had few problems with the engineering calculations or algorithms per se. Most felt confident that the calculations could be accurate with proper input data. However, nearly all respondents focused on the need to minimize the use of assumptions in these calculations and to devise ways of developing and using actual site-specific performance data instead. In general, respondents felt that the current engineering calculations tended to overestimate DSM savings for the reasons discussed below.

Survey respondents also felt that engineering calculations would be a long-term feature of DSM programs and DSM evaluation efforts. Some respondents pointed out that DSM program tracking systems require a savings estimate for each program participant and, in some instances, for each DSM measure. Engineering calculations were felt to be the most practical means of meeting these requirements at this time. 
The specific issues and shortcomings with engineering calculations identified by survey respondents include the following:

- Assumptions for operating hours are often inaccurate: Respondents consistently pointed out that operating hours at customer facilities are difficult to profile accurately for purposes of engineering calculations. Typical problems reported include poor information on equipment use during unoccupied periods; questionable operatinghour information reported by occupants and/or building management, even for occupied prriods; inconsistent information on HVAC control and thermostat use; and uncertainty as to whether walk-through survey data is representative of year-round operation.

- Published equipment performance data does not reflect "real-world" conditions: In the absence of measured field performance data, many respondents report that they are forced to rely on manufacturers' published test data as inputs to engineering calculations. However, they are convinced that this data does not accurately profile in-situ equipment performance at customer facilities because test conditions are not encountered in the field. This criticism was directed mainly at refrigeration, residential air-conditioning equipment, and cooling systems in commercial buildings.

- Analysis using engineering calculations is confounded by common space-conditioning equipment factors such as oversizing, partload performance, and maintenance: A number of respondents reported that there is little data on how those factors affect space-conditioning energy use and related DSM savings calculations. HVAC equipment that is oversized will tend to cycle more and use more energy to satisfy a given load than properly sized equipment. The effect of poor equipment maintenance on performance is known, but there is little or no data that quantify these effects for use in engineering calculations. Some manufac- turers' test data for part-load performance is available, but it reflects test conditions.

- Standard heating and cooling load calculations tend to overestimate space-conditioning loads: Load calculations for sizing heating and cooling equipment are sometimes performed for major DSM retrofits such as cool thermal storage systems. One respondent contends that these calculations overstate thermal loads and projected energy savings by a factor of two.

- Engineering calculations do not treat the "rebound effect": Ideally, energy-savings calculations would account for perceived customer tendencies to increase energy use to enjoy higher levels of energy services (such as comfort) with more energy-efficient equipment. However, this effect is not quantified and is the subject of continuing research. This comment could be extended to other DSM participant behavioral factors.

- Utility DSM tracking systems need to include more detailed customer-facility information: Given the important role of engineering calculations in the DSM field and the use of DSM program tracking systems to report participant savings, it is worthwhile to mention this observation. One respondent contends that DSM tracking systems should include more detail on customer-facility space types (for example, office, corridor, and conference room) because many key engineering calculation parameters vary by space type (such as operating hours, lighting levels, and thermostat settings). In addition, records should be kept of the types and capacities of customer equipment removed during DSM retrofits. These actions, over time, can help improve data assumptions.

In summary, the respondents expressed a lack of confidence in certain aspects of engineering calculations but certainly did not reject the approach. They seemed to feel that input data for these methods could be substantially improved through further research that addresses the 
topics outlined above. Priority areas for improvements are discussed at the end of this chapter.

\section{EXPERIMENTAL DESIGN AND SAMPLING}

Experimental design and sampling issues are treated together because in praciice they are often closely related. Experimental design, in the context of DSM impact measurement, generally refers to the selection of test groups of DSM participants; control groups of nonparticipants; methods for adjusting for differences between these groups; time periods, or intervals, for data collection; and methods for determining energy savings. Sampling to select individual members of test and control groups is integral to the design of a particular approach.

The California Collaborative's Measurement Protocols refer to "pre-post" experimental designs that compare test and control group data before and after DSM program implementation. This document also recommends a number of test and control group factors that should be taken into account and identifies acceptable measurement activities for estimating programimpact parameters. Other references provide information on the art and science of experimental design. EPRI's recent Guide to Current Practice (EPRI 1991) gives a complete and practical overview of the subject and includes a comprehensive bibliography. Experimental design is the topic of a past EPRI report, DSM Program Monitoring (EPRI 1988).

\section{Problems and Issues With Experimental Design and Sampling}

Utility M\&E and R\&D staffs, along with DSM researchers, are subject to a number of pressures and constraints in their work. Regulatory requirements, evaluation budgets, constant methodology developments, and deadlines for producing results must be handled effectively. Our survey respondents felt that experimental design is where many of these thorny trade-offs come together.
We asked the respondents to identify significant problems they face in these areas, including use of methods to extrapolate evaluation results to larger populations or regions. However, most respondents felt that extrapolation of results was generally not a significant problem because it is inherently treated in the experimental design. The major problems practitioners face in this area include:

- No accessible and comprehensive guide on experimental design for DSM impact evaluation is available: Although the DSM literature contains numerous references and case studies on impact evaluation, many respondents felt that such a guide was needed. In fact, one suggestion was to compile an "experience exchange" report listing various methods and approaches that have been employed in DSM evaluation efforts. This would facilitate identification of evaluation approaches that are compatible with the technical orientations and capabilities of different practitioners. Along similar lines, respondents also wanted more opportunities to network with their colleagues to keep up to date on methodological developments and to exchange evaluation experiences.

- Expectations for timing of results are overly optimistic: Respondents were nearly unanimous in their opinion that evaluation results take too long to produce. They also expressed frustration that timetables for delivering defensible results do not realistically account for mobilization and planning activities and normal project delays.

- Establishing baseline conditions is difficult: Most respondents reported difficulties with establishing pre-retrofit base case conditions or, in the case of new construction, current design practice baselines. The greatest difficulty was reported for savings estimation methods using field-monitored data in conjunction with simulation models. A number of respondents also identified a need to develop baseline data for applications ranging from Title 24 building-energy performance to equipment efficiency as re- 
flected in appliance shipments. However, development of such data was viewed as beyond the resources of individual utilities and as appropriate for cooperative, statewide efforts.

- The changing nature of programs and program participants over time is difficult to account for in sampling plans: A DSM program may be offered for several years, and a utility may redirect its marketing focus as it tries to maximize participation. Thus, first-year participants may have markedly different characteristics from those of participants in later years, complicating sampling of test and control groups. Some evaluation efforts use a multiyear sampling plan to better characterize program participants, but this strategy exacerbates the problem of timely results.

- DSM market-saturation effects cause difficulty in selecting control groups: Perhaps not surprisingly, substantial numbers of utility customers have participated in some aspect of DSM offerings. Some respondents have reported problems in finding enough nonparticipants for a proper control group. Approaches to treating control-group contamination are discussed in a recent EPRI report (1991).

- Sampling plans are often too contentious: This comment was heard more from respondents outside of California, especially with respect to collaboratively designed evaluation plans. Among practitioners, there appears to be considerable debate on how to handle practical trade-off questions mentioned previously (such as time and budget constraints, methodological limitations, and accuracy of results).

- Multi-objective optimization confounds experimental design and increases project complexity: While only one respondent raised this issue, it is appropriate to mention it here. One possible trend in future evaluation efforts is toward complex, large-scale projects, as seen in California and New England. As utility managers and regulators seek to maximize the information yield of these costly projects, imposing a multiple-objective burden could strain the current capabilities of practitioners. This respondent recommends the simple approach of measuring one parameter well.

- Sample designs often inhibit subsequent data analysis: Samples are often structured to estimate a single parameter (such as average end-use consumption) using a variety of multivariate regression techniques. In theory, changes in the dependent variable can be estimated by changing values in one or more of the independent variables. However, the independent variables are often correlated with one another. This multicollinearity can inhibit "what-if" sensitivity analyses. While the EPRI Guide to Current Practice suggests strategies to correct multicollinearity, one respondent has suggested that theoretical advances in sample design could facilitate these analyses. For example, prior knowledge of correlation patterns of the independent variables could be used to select uncorrelated regression variables that could be used in the sampling process to reduce multicollinearity. Under certain circumstances, these variables could also be assigned weights according to their relative importance, yielding an efficient, multidimensional sample design that is optimized for several parameters rather than just one.

- Integration of physical and behavioral models into statistical metiods is needed: Some practitioners believe that regression equations can be specified to account explicitly for the physical operation of DSM measures and occupant behavior to tie equation structure to real-world performance. If a regression equation is poorly specified, for example, larger quantities of insulation found in larger homes (vs. smaller homes) could yield the anomalous result that more insulation leads to higher heating energy use. However, an engineering equation incorporating insulation U-values, area of roof or wall insulated, and indoor-outdoor 
temperature difference would yield a more realistic result. Likewise, indoor space temperature setpoints could be specified as a function of energy price, household income, and energy-conservation attitudes. Thus, some observers believe that engineering and behavioral models should be integrated with more traditional statistical methods. Research done in this area suggests that further development work would be beneficial (EPRI 1988).

In summary, our respondents have identified very valid concerns. They seem to say that certain factors, external to measurement tasks, complicate their work. Frustrations over project deadlines and concerns with keeping up to date with methodological developments head the list. The other problems identified deal mostly with technical procedures that may provide opportunities for R\&D. Priority areas for improvement are discussed at the end of this chapter.

\section{METHODS FOR ANALYZING MEASURED DATA}

As part of this scoping study, we were interested in possible problems with analyzing measured data for DSM impact evaluation. In California, as elsewhere around the country, utilities and regulators are looking at fieldmonitored data as a viable approach to developing better estimates of DSM savings. However, field-monitoring projects generate formidable amounts of data that can be unwieldy to apply effectively.

The California Collaborative's Measurement Protocols identifies metering as an acceptable measurement activity for estimating the following program impact parameters: first-year savings, load-shape impact, useful life of DSM measures, and persistence of energy savings. EPRI's Guide to Current Practice also identifies a number of advantageous applications for enduse metered data within statistical models. Other DSM evaluation projects rely heavily on field-monitored data, most notably that of
Northeast Utilities in Massachusetts and Connecticut (NU 199()), which uses both end-use and short-term monitoring techniques. Field monitoring continues to attract interest and acceptance as a major data-collection technique, and many observers expect this trend to continue.

\section{Problems and Issues With Data Analysis}

We were somewhat surprised that respondents did not report significant problems with database management and statistical analysis of field-monitored data. Indeed, most felt their organizations had sufficient capabilities for these types of data manipulation. The problems that were identified included the following:

- Data needs are often not well thought-out during project planning: This has been a continuing problem with field measurement for many years. Too often, critical data oversights cause analysis problems long after metering equipment and sensors are specified and installed. To remedy these plarning oversights, measurement practitioners have developed a number of monitoring protocols to minimize these difficulties (Misuriello 1990; MacDonald 1989; Szydlowski 1989; Ternes 1987). However, field-monitoring protocols for the specific task of DSM impact evaluation have yet to be published, and existing protocols may not be well known in the DSM community because they are found primarily in American Society of Heating, Reírigerating and Air-Conditioning Engineers (ASHRAE) literature.

- Data validity and quality control are still problems: Missing and erroneous data has often plagued field-monitoring projects. However, most of these problems have arisen from less reliable field-data acquisition systems than are available today. An overview of quality-control methods for field-monitoring projects is given by Misuriello (1990). 
- Clear guidelines and literature on how to use measured data with simulation models, such as DOE-2, are not available: It is a challenging task, involving the systematic distillation of large amounts of data, to specify end-use equipment usage profiles, space temperatures, HVAC performance parameters, ventilation and infiltration, and similar inputs. Other measured data must be processed to check the model's output. Despite widespread use of calibrated sinıulation models, few literature sources address specific techniques to perform this calibration. Some projects provide documentation on this method. Methods for modeling new commercial construction for the BPA "Energy Edge" program are provided by Kaplan (1990). Calibration of commercial building retrofit models for a Seattle City Light project is addressed by Schuldt (1988).

- Obtaining insights from measured data is difficult: We began this discussion by noting that processing and manipulation of field-monitored data did not present any significant problems, accoraing to our respondents. However, many pointed out that it was difficult to look at this data in a way that provided insights into end-use consumption patterns and building operational practices. These respondents wished for new graphic-analysis hardware and software that could quickly manipulate large data sets for exploratory data analysis. Some recent developments could meet these needs. For example, Pacific Gas \& Electric Company's (PG\&E's) ACT2 technology demonstration project is developing an advanced data processing system with strong data-visualization capabilities. Also, a new data-visualization workstation, the Electric Eye, has been announced by a Singapore- and Houston-based firm, Supersymmetry Services PTE Ltd.

In summary, methods for analyzing field-monitored data may be less problematic than other issues addressed in this scoping study. However, there are still areas of concern, such as protocols for project planning, data-point specification, data quality control, and data synthesis. Priority areas for improvement are discussed at the end of this chapter.

\section{USE OF WHOLE-BUILDING DATA FOR IMPACT EVALUATION}

Whole-building data is routinely collected by utilities, usually in conjunction with PURPA studies (load research data is required by the Public Utility Regulatory Policies Act of 1978). This time-series data represents total-building electric (or natural-gas) consumption and is often collected at 15 -minute or 1 -hour intervals. Whole-building data is relatively inexpensive to collect, and procedures for carrying out such studies are well known.

Whole-building data by itself is insufficient for DSM impact analysis. This data must alsu be analyzed in conjunction with building characteristics and operation information (MacDonald 1989). Techniques that use (or could potentially use) this data may incorporate engineering algorithms and/or statistical methods to disaggregate whole building energy use into end-uses. At present, however, procedures for applying whole-building data to DSM impact evaluation have not seen substantial use, although specific uses have been proposed (ESEERCO 1990). At least one large-scale DSM evaluation effort will use whole-building data as part of the approach (NU 1990). These applications include:

- Conditional demand analysis (CDA), with a "pre/post" (or first-difference) model specification (EPRI 1991).

- The statistically adjusted engineering (SAE) model, which decomposes wholebuilding loads into end-uses (EPRI 1991).

- The end-use disaggregation algorithm (EDA), an engineering method that uses statistical analysis of hourly load data and its temperature dependence to estimate end-use load shapes (Akbari 1988). 
- The hybrid statistical/engineering model (HSEM), used to develop adjustment factors applied to DSM savings determined through energy audits or similar engineering calculations. Input to HSEM comes from on-site equipment and operating surveys and from total building load meters. HSEM also uses a small sample of end-use monitoring sites for calibration. This approach has been proposed for a statewide DSM evaluation effort in the siate of New York (ESEERCO 1990).

- The engineering calibration approach (ECA), which uses the ratio estimate method to develop factors that adjust DSM savings estimates in the utility DSM tracking system. The ad, ustment depends on the relationship between DSM savings determined in the field (through end-use metering) and engineering estimates of the same savings. In its application at Northeast Utilities, the ECA approach also incorporates a supporting sample of whole-building metered sites for which DSM savings are determined through calibrated engineering models (NU 1990).

\section{Problems and Issues With Whole- Building Data for Impact Evaíuation}

Since the DSM field has little experience with these types of whole-building data methods, our respondents had few comments in this area. However, a few respondents noted that the statistical methods (such as CDA and SAE) may work best in residential applications and in instances where there are large, distinct loads and savings. Some respondents considered the ECA and HSEM approaches to be state-of-theart methods. In summary, these methods are quite promising because they draw on the strengths of statistics, engineering, and metered data. More application experience and cooperative $R \& D$ improvements are needed to prove their potential.

\section{PERSISTENCE OF ENERGY SAVINGS}

Probably the biggest unanswered question in DSM is the persistence of energy savings. In some ways, it may be the most important one because the availability of DSM savings over the life of the measure is critical for DSM to be deemed reliable as a resource. Yet there are few published studies on this topic and no broad consensus on how to measure this parameter. One of the obvious problems is that a DSM program may not have been in the field long enough for sufficient data to be collected. In fart, in three of the four references on this topic in EPRI's Guide to Current Practice, the study periods were three years. The fourth study examined savings persistence over six years. These periods are substantially shorter than the useful lives of DSM measures reported in the California Collaborative's Measurement Protocols (10 to 15 years for many measures). For reporting purposes, California utilities use a "decay factor" to approximate assumed degradation of DSM savings over time.

\section{Problems and Issues With Persistence Studies}

There is little debate within the DSM community that persistence studies are needed. Indeed, recent proposals from the California Energy Commission indicate that a major study may soon be underway. We put this topic before our survey respondents, and they identified a number of persistence-study problems and issues that we have organized as follows:

1. Scope of study and definition of parameters related to persistence: Respondents recommended that the scope of such a study be viewed broadly and take into account these parameters:

- Measure lifetime

- Measure performance or efficiency decay 
- Measure failure, especially in the first year

- Measure maintenance and repair

- Measure installation and commissioning

- Changes in the building stock (renovations, alterations)

- Behavioral persistence (customer removal of measure)

- Occupant changes

- Rebound effects

- Surge effect, or additional measures added by customer after initial program participation

- Inertia effect, or slow customer implementation of measures

2. Study design: Respondents had several suggestions on structuring and administering such a study, including:

- Use longitudinal, time-series experimental design to track a sample of DSM measures and/or participants. One respondent observed that long-term health-care studies may provide a useful model.

- Sample participants in persistence studies over time to ensure a good mix of program participants.

- Establish comparison baselines using control groups if possible.

- Realistically evaluate the difficulty of administering such a long-term study. Consider the persistence of evaluators!

- Consider the usefulness and durability of results. Will persistence be deter- mined for measures not used in future DSM programs?

3. Study resources: Nearly all respondents agreed that persistence studies were appropriate for joint, statewide, or regional studies since the problem is generic. Respondents also agreed that these studies might be beyond the resources of individual organizations, and resource pooling was necessary.

\section{PRIORITY AREAS FOR IMPROVEMENT}

At this point, we want to recommend a number of R\&D opportunities based on the topics and issues discussed in this chapter. We are recommending that three priority levels be considered for reviewing potential R\&D projects:

Priority 1: R\&D opportunities that may fill critical gaps in information or methodology needed to meet basic DSM evaluation requirements.

Priority 2: R\&D opportunities that may produce new or advanced information or methods that could replace less affective ones.

Priority 3: R\&D opportunities that enhance or increase the sophistication of currently workable methods.

\section{Specific R\&D Opportunities}

Our recommendations for Priority 1 research projects are to:

1. Design and implement a comprehensive statewide persistence study addressing the topics and concerns previously discussed. Resources and research should be coordinated and incorporated with other efforts nationwide.

2. Develop improved data and methods for engineering calculations, including charac- 
terization of actual DSM measure performance, customer operating characteristics, and improvements to estimating interaction effects. Establish specific sector/enduse/measure priorities according to analysis of annual DSM reports for 1989-1990.

3. Accelerate application and testing of impact estimation methods using wholebuilding load data (ECA and HSEM methods, for example). Emphasize collaborative $R \& D$ approaches for improvements.

4. Accelerate development and testing of short-term DSM impact techniques for priority sectors/end-uses/measures.

5. Accelerate development and testing of advanced statistical energy-analysis models that explicitly integrate engineering and behavior models.

Priority 2 research project recommendations include:

1. Developing, testing, and disseminating workable guidelines and procedures for using measured data for simulation-model calibration.

2. Preparing and disseminating manuals or literature guides on experimental design for DSM impact evaluation. (For example, an "experience exchange" report could provide a menu of evaluation approaches for a particular application.) Provide continuing support through periodic updates and $M \& E$ staff networking opportunities.

3. Planning and specifying statewide, cooperative baseline performance data compilation and study. Consider key baseline performance topics such as new construction (Title 24) and appliance efficiency. Identify systematic procedures for periodic updates.

4. Perform R\&D multidimensional sampling effects in energy-performance modeling.
Lastly, research projects recommended as Priority 3 are:

1. Preparing and disseminating guidelines or protocols for planning data-collection projects. This material should address data-point specification oversight and QA/QC procedures.

2. Developing and testing improvements to DSM administrative tracking systems that add more detailed customer information on space types, operating conditions, and preretrofit technologies. This work should be carried out in support of Priority 1 projects 2 and 3 . 
Very detailed information is published about the measured output and operation of power plants, but comparable information on the performance of demand-side programs and measures is generally not available (Hirst 1990). Utilities must obviously install electricity and gas meters at each customer facility for revenue and billing purposes. Accurate and inexpensive meters have been available for decades. Unfortunately, such hardware is not available to meter DSM savings. With today's technology, it is currently not practical to install "lostrevenue" meters at each DSM participant facility to measure "nega-watt" hours, even when regulatory compensation for lost revenues is allowed. Thus all determinations of DSM savings today are really estimates, even when fieldmonitored data is used in savings computations.

This chapter discusses a number of problems and issues regarding the application of field-monitoring methods to DSM impact evaluation. In this context, field monitoring refers to the gathering of time-series building energy use data in the field, using special-purpose recording equipment. We do not include utility-bill analysis as a field-monitoring activity in this discussion. (However, the California Collaborative's Measurement Protocols defines billing data as metered data, along with end-use consumption data.)

\section{ROLE OF FIELD MONITORING IN DSM IMPACT EVALUATION}

In the last chapter, we identified several applications of field monitoring to DSM impact estimates. These include:

- Use of end-use data to augment certain statistical techniques such as regression models, statistically adjusted engineering mod- els, and conditional demand analysis methods (EPRI 1991).

- Use of end-use data to calibrate buildingsimulation models used to determine savings. These include mudels for pre/postretrofit analysis, models for participant energy-efficient new construction program participants, and calibration of HSEM.

- Use of end-use metered data to determine DSM savings for use in ratio-estimator methods. At Northeast Utilities, this application also uses ECA with an intermediate sample of whole-building metered sites.

- Use of short-term rnonitoring techniques to identify pre/post loads and load reductions and to verify pre/post operating hours. This data is then used in calibrated engineering calculations (spreadsheet models, for example) to estimate annual savings.

For a variety of reasons, we think that more evaluators will use field monitoring to a greater extent. For example, o: rr regulatorypractices survey found a preference for monitoring-based methods for DSM evaluation. However, the main barrier to increased use of monitoring methods is their perceived high cost. Indeed, we expect that more widespread experience with field-monitoring techniques will not only identify new DSM evaluation applications, but also identify additional problems requiring $R \& D$ solutions.

\section{MONITORING: HARDWARE NEEDS}

In structuring our survey questionnaire to address problems and issues in this area, we se- 
lected a number of subtopics in which we thought respondents would identify problem areas appropriate for $R \& D$ projects. The two areas we decided to focus on are innovations needed to better adapt monitoring hardware to DSM impact evaluation and ways to reduce the cost of DSM impact metering. Our survey respondents identified these monitoring hardware needs:

- Nonintrusive monitoring systems (NIMS): The NIMS approach, if successfully commercialized, could dramatically change field-monitoring practices. Nonintrusive systems will measure total building power (at the pole or meter socket) while tracking characteristic power-line disturbances caused by appliances and other end-use equipment. NIMS associates changes in power usage with specific power-using equipment and keeps track of on/off cycles. Using on-site data processing, NIMS will be able to report appliance use by time of day. EPRI has demonstrated this technology and is currently selecting a commercialization contractor. While it is intended for load research applications, it would be adaptable to DSM impact evaluation.

- Low-cost monitoring systems: While monitoring projects are costly, much of the cost is for system design and installation. In addition, certain components of monitoring systems are costly, such as kilowatt transducers. Our respondents thought that some innovations could reduce costs.

- Power-line carrier (PLC) technology: PLC devices send and receive data over power lines. This could reduce wiring and installation costs and reduce use of auxiliary data loggers in remote locations.

- Low-cost, solid-state kilowatt transducer or "smart" current transformer using digital technology.

- Lou-cost proxy measurement devices that monitor equipment run-times: At least one "stick-on" run-time meter for light fixtures is on the market.
- Intrabuilding sampling techniques so that not all spaces and end-uses need be monitored.

- Accommodation of DSM program participants to monitoring equipment: For example, requiring the installment of temperature sensor wells in pipes on major retrofit projects.

Not all these suggestions will prove practical or cost-effective. However, the thrust of the comments was to do some systematic analysis for all aspects of monitoring systems to reduce costs. This suggests that a "value-engineering" approach could be employed; that is, a systematic analysis that identifies alternate ways of achieving equivalent performance at a lesser cost.

- Specialty "field kits" for technology evaluntions: Some respondents wanted preengineered field-data acquisition systems for specific tasks such as pre/post lighting assessments, HVAC efficiency testing, and motor-load testing. In addition, they wanted these field kits to be bundled with data-analysis software.

- Self-monitoring appliances: One respondent suggested that a "smart-house" approach be applied to appliances by having energy measurement devices built in at the factory. This may actually be more practical than it first sounds because utilities do have substantial market influence. For example, many observers think that the growing compact-fluorescent market is due to rebate and give-away programs. Under these conditions, utilities may be in a position to negotiate this type of modification.

\section{MONITORING SOFTWARE NEEDS}

Many of the responses about software for monitoring systems were the same as for the exploratory data-analysis and data-visualization topics discussed in the last chapter and are 
not repeated here. Other software needs include:

- "Sinart" data loggers: A few respondents suggested that data loggers include more on-site data-processing capabilities than just logging data. A smart data logger could, for example, compare monitored airconditioner performance to published performance specifications and report variances. These types of functions could reduce analysis costs and improve data quality.

- Expert system applications: A number of field-monitoring activities are repetitive and, to some extent, rule-based. For example, site measurement plan preparation typically requires assignment of building electric circuits according to prescribed enduse definitions. This type of activity could possibly be aided by an expert system.

\section{MONITORING PROTOCOL NEEDS}

Many respondents were interested in methodology improvements that would save time in implementing projects and delivering results. Once again, we heard the need for the short-term monitoring methods described in the last chapter. Other comments dealt with standardizing procedures:

- Standard procedures for common monitoring tasks: One respondent felt that efficiencies in field operations could be gained by developing standardized procedures for such tasks as monitoring-system installation, data-collection procedures, and use of $\mathrm{QA} / \mathrm{QC}$ methods. This would improve consistency and reduce learning time.

- Site measurement plan "recipe book": Along the same lines, another respondent felt that monitoring-system design time could be reduced by developing pre-engineered solutions to technology-assessment monitoring applications. For example, engineering "templates" could be designed to guide measurement plans for lighting retrofits, daylighting systems, air-conditioner replacements, and similar DSM measures. These templates could then be adapted to site-specific conditions.

\section{PRIORITY AREAS FOR IMPROVEMENT}

We now want to recommend a number of $R \& D$ opportunities based on the topics and issues discussed in this chapter on field-monitoring issues. However, we need to point out that this type of R\&D may be somewhat different from, say, that for data-analysis methods. For example, many of the cost-related problems may be due to the small size of this specialty hardware market. As demand for this equipment grows nationally, some price improvements may occur. Some practitioners also felt that monitoring-equipment vendors are in close touch with their utility customers and that the market would respond to these needs. However, the veracity of these predictions remains to be seen.

Our recommendations for Priority 1 research projects are as follows:

1. Initiate a value-engineering study to analyze cost-reduction opportunities within monitoring projects. The scope of the study would include data loggers, senisors and proxy measurements, data transmission, installation, calibration, and maintenance. Results would be transferred via industry workshops.

2. Pursue development of the specialty-testkit approach to support accelerated delivery of short-term monitoring methods.

Priority 2 research project recommendations are as follows:

1. Develop and test prototype expert-system applications for field-monitoring projects. Identify repetitive, rule-based activities. Prepare rules using knowledge-engineering methods. 
2. Develop and disseminate "recipe book" for site measurement plan preparation. Define a comprehensive set of engineering templates for on-site assessment of DSM measures in all sectors.

3. Develop and test theory and procedures for sampling energy use within buildings so that not all spaces and end-use equipment need to be monitored.

Lastly, Priority 3 research project recommendations are to conduct a feasibility study on selfmetering appliances and other DSM devices; explore technical, cost, and market constraints; and identify the potential for miniaturizing energy-use or run-time meters for small devices such as compact fluorescent lamps. 


\section{ISSUES IN EVALUATING DSM MEASURES}

Knowledge of DSM technology performance is critical to all aspects of DSM. The expected performance of DSM measures is used to screen programs, to forecast their effects, and to value their anticipated load reductions. Performance data is key to identifying customer benefits for program marketing. Determining the actual performance of DSM measures is the essence of impact evaluation.

In California, considerable emphasis is placed on the evaluation of individual DSM measures as part of the evaluation of DSM programs. The CPUC's Demand-Side Management Reporting Requirements Manual requires reporting of DSM impacts and costs by measure as well as by other categories. The California Collaborative's Measurement Protocols is, to a large extent, measure-oriented; it recommends that major load impact parameters be estimated for each measure in each DSM program.

Measure-specific impact evaluation is complicated by the number of measures offered through programs. CIEE recently conducted an informal survey to list the DSM measures offered by five California utiiities. They cataloged 154 measures in the commercial sector and 67 measures in the residential sector. The inventory may be even higher if one considers "custom" measures identified by program participants themselves. Thus, the sheer number and diversity of DSM measures make impact evaluation a daunting task, apart from any technical shortcomings in assessment techniques.

We were interested in the specific problems faced by evaluation practitioners in assessing the performance of these measures. On our survey form, we asked respondents to identify several measures they found most difficult to evaluate. As an interview and discussion aid, we also listed the top three or four DSM measures in the residential, commercial, industrial, and agricultural sectors.

We also asked respondents about impact evaluation for information and energy audit programs. We received mixed opinions. Some respondents felt that evaluation efforts should focus only on true resource ("hardware") programs that are alternatives to supply-side options. Others stated that these programs are just part of the DSM program delivery process and not worth evaluating from the standpoint of savings. Most respondents felt that impact evaluation of these programs would require very large samples, since they would expect that any savings attributable solely to them would be small. Nonetheless, utilities conduct impact evaluations on these programs. Recently, San Diego Gas \& Electric Co. (SDG\&E) commissioned an evaluation of its Non-Residential Audit program, finding evidence of high adoption rates for recommended measures and high realization of estimated savings (SDG\&E 1991).

Overall, responses to our questions were surprisingly uniform. Nearly all respondents stated that HVAC measures were the most difficult to evaluate. Beyond that, respondents were troubled by measures with relatively low savings impacts (such as residential compact fluorescent lamps), low-incidence measures (those infrequently implemented, for example), and custom measures. A couple of respondents also raised evaluation concerns about motor retrofits. 


\section{PROBLEMS AND ISSUES WITH EVALUATING HVAC MEASURES}

DSM impacts from HVAC measures are significant in California according to data on reported savings. As we showed earlier in Tables 2 and 3, HVAC measures account for about $45 \%$ of reported residential sector DSM savings and about $30 \%$ of nonresidential sector savings. With this kind of impact, good evaluation tools for HVAC measures appear to be needed. Here are the problems and issues our respondents identified:

- Difficulty in establishing baseline HVAC use: Respondents reported that high variability in HVAC use among participants (such as inconsistent thermostat control and other behavioral factors) makes it difficult to establish baseline conditions.

- Determining field HVAC efficiency: A number of factors contribute to this problem, according to survey respondents. First, rated nameplate data does not reflect actual HVAC performance in the field. This problem is common to all types of equipment, from room air conditioners to 500-ton chillers. Second, efficiency tests require measurement of energy input and the thermal load being met. Field measurement of air-side and water-side loads is prone to inaccuracy. This difficulty was reported even by practitioners measuring gas-furnace performance. Third, pre/post evaluations of HVAC retrofits involve some type of normalization for weather effects and changes in thermal loads. This is often done through simulation models, but model limitations are problematic.

- Measuring infiltration and ventilation: Respondents observed that this was less of a problem in residences, where blower door testing is practical. In commercial buildings, though, determining these parameters is largely educated guesswork. Ventilationdata inputs for simulation models may be taken from HVAC blueprints when avail- able or determined by judgment. Field-test procedures using tracer-gas decay have been documented by the National Institute of Standards and Technology (NIST), but they may be too complicated and costly to use for DSM applications.

- Determining interactive effects: There appear to be two aspects of what is termed DSM measure interaction. To some researchers, the term interaction means multiple measures affecting the same end-use. For example, roof insulation and a set-back thermostat will affect heating-energy use interactively. The impact of reduced lighting wattage on cooling requirements is sometimes called a secondary effect. Whatever terms are used, these effects are very difficult to evaluate. Indeed, it may not be practical to differentiate interactive effects (insulation, glazing, and weatherization) because of measurement or modeling limitations. Secondary effects may be easier to determine using pre/post experimental design and normalization techniques. We should point out that some respondents questioned whether it was worthwhile to pursue these measurements because they believed the effects to be small in most cases.

- Evaluating custom HVAC measures: Some respondents were concerned with evaluating custom DSM measures resulting from customer-initiated programs. They viewed these almost as case studies, since the DSM package can be unique or unusual. HVAC contro! modifications, including energymanagement systems, were cited as examples of custom measures. There were concerns that custom DSM installations require a disproportionate effort to evaluate, compared to more standard DSM offerings. 


\section{PROBLEMS AND ISSUES WITH EVALUATING OTHER DSM MEASURES}

Our respondents are not entirely preoccupied with HVAC measure problems. Other DSM measure assessment concerns include:

- Measures with low unit impacts: Most respondents cited residential compact fluorescent bulbs as an example. These types of measures pose a real dilemma because the savings impact is too small to justify an end-use field measurement and to be reliably distinguished through billing analysis or similar methods. Yet the measure may be widely implemented and, in the aggregate, may provide substantial savings. Note that Table 2 shows that about $19 \%$ of residential savings are for lighting measures. Engineering calculations are typically used for evaluation, but practitioners, once again, have little confidence in the assumptions about wattage reduction, hours of use, and so forth.

- Infrequently implemented measures: These are DSM measures with low penetration that are often categorized as "various" for the residential sector and "miscellaneous" for the nonresidential sectors. According to the reported savings data presented in Tables 2 and 3, these measures appear substantial: $13 \%$ of residential savings are from "various" measures, while "miscellaneous" measures account for about $25 \%$ of nonresidential savings. Here another dilemma presents itself: In the aggregate, this class of measures can produce significant savings, but individual types of measures may not appear with sufficient frequency to be analyzed with statistically based methods.

- Motor issues: One respondent cautioned that motor savings should be looked at more carefully, especially with regard to using published performance data for engineering calculations. This respondent reports that energy-efficient motors operate at higher revolutions per minute (RPMs) than conventional motors and that their nominal efficiency ratings are specified at these higher nominal RPMs. Thus, the actual RPMs of the motor application need to be taken into account for savings estimates. Further concerns were reported for variable-speed motor drives. Savings may be overestimated in instances where the load on the motor does not vary as expected.

\section{PRIORITY AREAS FOR IMPROVEMENT}

We can now recommend a number of R\&D opportunities based on the topics and issues discussed in this chapter on evaluation of DSM measures. We have discussed the important impacts attributed to HVAC measures and the numerous practical difficulties in determining these impacts at customer facilities. We have also looked at the surprisingly high impacts attributable to vaguely identified DSM measures-those that are "various" and "miscellaneous" -and others that have low unit impacts. It is apparent that there are significant information gaps in these areas.

Our recommendations for Priority 1 research projects are as follows:

1. Develop and test HVAC field-measurement techniques for determining field efficiency. Identify possible correction factors for nameplate data. Develop methods for baseline characterization. Coordinate with engineering-calculation improvements.

2. Develop and test methods to evaluate lowimpact, high-penetration measures such as compact fluorescent bulbs.

3. Identify the composition of DSM measures in the "miscellaneous" and "various" categories. Develop evaluation methods for low-frequency measures.

Priority 2 research project recommendations are to develop engineering field test data on motors 
and motor drives in typical retrofit settings and to develop and test simplified impact-evaluation methods.

Lastly, research projects recommended as Priority 3 are to resolve issues with interactive and secondary effects, identify the magnitude of impact for significant measures in all sectors, and determine the need for ongoing evaluation of these effects in full-scale DSM programs. 


\section{RECOMMENDATIONS FOR R\&D OPPORTUNITIES}

Our goal in this effort has been to identify viable $R \& D$ opportunities that can improve capabilities to determine the energy and demand reductions achieved in customer facilities through DSM programs and measures. We surveyed numerous practitioners in California and elsewhere to identify the major obstacles to effective impact evaluation, drawing on their collective experience. We have attempted to synthesize this information, adding our own perspective and experience to those of our survey respondent colleagues. In addition, we took into account a number of insights provided in EPRI's recent Guide to Current Practice and in the California Collaborative's Measurement Protocols.

We have looked into three topic areas of significant interest to CIEE: data analysis issues, field monitoring issues, and issues in evaluating DSM measures. Across these three topic areas, we have identified 22 potential opportunities to which we have assigned a priority level. These priority levels are:

Priority 1: R\&D opportunities that may fill critical gaps in information or methodology needed to meet basic DSM evaluation requirements.

Priority 2: R\&D opportunities that may produce new or advanced information or methods that could replace less effective ones.

Priority 3: R\&D opportunities that provide enhancements or more sophistication for currently workable methods.

\section{SPECIFIC RECOMMENDATIONS}

These $R \& D$ recommendations are summarized in Table 1. Each R\&D opportunity is referenced by its topic area (such as "Analysis" from Chapter 3) and by its priority. Please refer back to the appropriate chapter for the full description of each recommended project.

The Priority 1 projects, in our opinion, would initiate research that addresses the most basic concerns of the impact-evaluation community:

- A major California persistence study to determine the long-term reliability of DSM resources. We recommend a cooperative project involving all stakeholders. Since this is an important national technical and policy issue, we would also recommend coordination with, and cooperative funding by, national research organizations.

- A concerted effort to improve engineering calculations. We believe that engineering calculations are a permanent feature of DSM activities and that research investments in this area will pay long-term dividends.

- Integration of statistical engineering and behavioral models. This is recommended because of the widespread use of regression analyses in DSM evaluations and the potential benefits of incorporatils? engineering and behavioral factors into these analyses.

- Better use of field-monitored data for impact evaluation. We feel this potential has barely been tapped. Several projects can overcome current barriers. Problems with high cost could be addressed through systematic value engineering. Timely evalua- 
tion results could be achieved through advanced short-term monitoring techniques. Specialty monitoring approaches, such as "field kits" and HVAC field testing methods, would provide reliable data on these hard-to-measure parameters. Evaluation methods specifically tailored to wholebuilding data have enormous potential because they could leverage the considerable capabilities of load-research departments.

- Addressing low-impact and low-frequency measures. We recommend developing methods in this area primarily because of the relatively high DSM savings attributed to these measures and because of the apparent lack of knowledge about exactly what measures they are.

Our Priority 2 recommendations, to a large extent, promote technology transfer as well as initiating development of new methods:

- In the technology transfer area, we acknowledge the expressed needs of our survey respondents to have better information on experimental design, simulation-model calibration, site measurement plan preparation for monitoring projects, and motor performance. All these will contribute to the improved effectiveness of practitioners.

- Collinear variables may pose a growing problem for practitioners as DSM impact evaluations may increasingly rely on regression analysis techniques. We recommend that advanced sampling techniques that mitigate multicollinearity be explored.

- Artificial intelligence and expert systems have shown their potential in other facets of the utility industry. We think DSM impact evaluation can benefit as well. Some of the repetitive, rule-based activities on field-monitoring projects, such as measurement-plan development, are good candidates for R\&D.

- Intrabuilding sampling for energy-monitoring purposes has not, to our knowledge, been tested. We are unsure of chances for success, but the potential cost-reduction benefits lead us to recommend it. However, this concept may presume a higher level of knowledge of building energy use than we have at present.

The Priority 3 recommendations could enhance some of the methods we use today:

- Oversights in planning data-collection projects are still being reported. Standardized protocols could be of assistance to many practitioners.

- Improvements in administrative tracking systems will be a permanent part of DSM activities. Improvements to provide more accurate reporting of savings and to support other evaluation activities (sampling frames, for example) are worth further development.

- We agree with our respondents that the magnitude of interactive and secondary effects is uncertain but is likely to be small in most cases. We think these issues should be resolved.

- Lastly, the idea of self-monitoring appliances, and the approach of using DSM market clout to bring them about, was too intriguing not to be included here.

\section{NEXT STEPS}

CIEE is considering these $R \& D$ recommendations for possible inclusion in the Technology Performance Analysis topic area of its ERP program. CIEE will lead the review of these recommendations with California utilities, regulators, and other parties. CIEE also solicited the comments of interested parties at a special workshop (May 15, 1991) and at the CIEE First Annual Conference, held August 27-29, 1991, at the University of California, San Diego. 
ACEEE 1991. State of the Art of Energy Efficiency, Future Directions. Edited by Edward Vine and Drury Crawley. Washington, D.C.: American Council for an Energy-Efficient Economy.

Akbari, H. 1988. "An algorithm to disaggregate commercial whole-building hourly electrical load into end-uses." Performance Measurement and Analysis, Proceedings of the 1988 ACEEE Summer Study on Energy Efficiency in Buildings, Vol. 10. Washington, D.C.: American Council for an Energy-Efficient Economy.

California Collaborative 1990. Report of the Statewide Collaborative Process: An Energy Efficiency Blueprint for California, Measurement Protocols for DSM Prograins Eligible for. Shareholder Incentives.

CIEE 1991. Draft Multiyear Research Plan, 1991. Berkeley, Calif.: California Institute for Energy Efficiency, Lawrence Berkeley Laboratory.

CPUC 1990. Demand-Side Management Reporting Requirements Manual, Fourth Edition. San Francisco, Calif.: California Public Utilities Commission.

EPRI 1991. Impact Evaluation of Demand-Side Management Programs, Volume 1: A Guide to Current Practice. Prepared for the Electric Power Research Institute, Palo Alto, Calif. (EPRI CU-7179, Project 2548-11), by R. Hagler, Bailly, Inc. (Boulder, Colo.).

EPRI 1988. DSM Prograin Monitoring. Prepared for the Electric Power Research Institute, Palo Alto, Calif. (EPRI EM-5706, Project 2548-1), by Applied Management Sciences (Silver Spring, Md.).

ESEERCO 1990. Final Report: Demand-Side Management Program-Evaluation Scoping Study, ESEERCO Project EP90-34. Prepared for Empire State Electric Energy Research Corp., New York, N.Y., and Long Island Lighting Company, Hicksville, N.Y., by Xenergy Inc. (Burlington, Mass.).

Hirst, E. 1989. "Evaluating energy-efficiency programs: A personal view of progress and potential." Energy Program Evaluation Conservation and Resource Management. Chicago, Ill.: Proceedings of the August 23-25, 1989 Conference.

Hirst, E. 1990. Balancing the Scales: Data on Electricity Supply and Demand Resources. (ORNL/CON306). Oak Ridge, Tenn.: Oak Ridge National Laboratory.

Hopkins, M.E. 1990. "Least-cost planning regulation for gas utilities." Public Utilities Fortnightly. Arlington, Va.

Kaplan, M., B. Jones, and J. Jansen 1990. "DOE-2.1C model calibration with monitored end-use data." Performance Measurement and Analysis, Proceedings of the ACEEE 1990 Summer Study on Energy Efficiency in Buildings, Vol. 10. Washington, D.C.: American Council for an Energy-Efficient Economy. 
MacDonald, J.M., and M.B. Gettings 1989. A Protocol for Monitoring Energy Efficiency Improvements in Commercial and Related Buildings. (ORNL/CON-291). Oak Ridge, Tenn.: Oak Ridge National Laboratory.

Misuriello, H. 1990. "Field monitoring of building energy performance." Performance Measurement and Analysis, Proceedings of the ACEEE 1990 Summer Study on Energy Efficiency in Buildings, Vol. 10. Washington, D.C.: American Council for an Energy-Efficient Economy.

NU 1990. Conservation and Load Management Evaluation Plan 1990-1994. Rocky Hill, Conn.: Demand Program Planning and Analysis Section, Conservation and Load Management Department, Northeast Utilities.

Schuldt, M., L. Caldwell, C. Cleary, and V. Wong. "Conservation opportunities in commercial buildings: Utilizing end-use load data to stimulate and measure conservation savings." Performance Measurement and Analysis, Proceedings of the 1988 ACEEE Summer Study on Energy Efficiency in Buildings, Vol. 10. Washington, D.C.: American Council for an Energy-Efficient Economy.

SDG\&E 1991. Final Report: SDGEE Non-Residential Audit Evaluation. Prepared for San Diegu Gas \& Electric Co. by Regional Economic Research, Inc. (San Diego, Calif.).

Szydlowski, R.F., and R.C. Diamond 1989. Data Specification Protocol for Multifamily Buildings (LBL-27206). Berkeley, Calif.: Lawrence Berkeley Laboratory.

Ternes, M.P. 1987. A Data Specification Guideline for DOE's Single-family Building Energy Retrofit Research Program. Atlanta, Ga.: American Society of Heating, Refrigeration, and Air-Conditioning Engineers, Inc. 


\section{Appendix A PARTICIPANT LIST}

\section{R\&D PARTICIPANTS}

Winston Ashizawa

Sacramento Municipal Utility District P.O. Box 15830

Sacramento, California 95852

(916) $732-5494$

Mike Baker

Principal

SBW Consulting, Inc.

2820 Northrup Way, Suite 230

Bellevue, Washington 98004

(206) 827-0330

Larry B. Barrett

President

Barrett Consulting Associates

P.O. Box 60429

Colorado Springs, Colorado 80960

(719) 634-4468

Carl Blumstein

University of California/UERG

T-9, Room 216

Berkeley, California 94720

(510) 486-9588

Benson H. Bronfman, Ph.D.

Bronfman \& Associates

602 NE Hazelfern PI.

Portland, Oregon 97232

(503) 231-8643

Merwin L. Brown

Pacific Gas \& Electric

3400 Crow Canyon Rd.

San Ramon, California 94583

(510) 866-5560)
Michael Cheng

Pacific Gas \& Electric

3400 Crow Canyon Rd.

San Ramon, California 94583

(510) 973-3021

Brian Coates

Seattle City Light

1015 Third Ave., Room 819

Seattle, Washington 98104-1198

(206) 684-3729

Chris Dent, P.E.

Principal

Pacific Science \& Technology

833 Wall St., Suite B

Bend, Oregon 97701

(503) 388-4774

Wayne Estey

Connecticut Department of Public Utilities

1 Central Park Plaza

New Britain, Connecticut 06051

(203) 827-1553

Rick Fleming

Ontario Hydro

700 University Ave. C27 E1

Toronto, Ontario, CAN M5G 1X6

(416) $592-9236$

Steve Galanter

Southern California Edison

P.O. Box 800

2244 Walnut Grove Ave.

Rosemead, California 91770

(818) 302-3574 
Fred Gordon

Pacific Consulting Services

1920 SE Mulberry Ave.

Portland, Oregon 97214

(503) 233-6543

Jorge H. Guierrez

Senior Associate Engineer

Engineering Department

Southern California Gas Co.

8101 South Rosemead Blvd.

Pico Rivera, California 90660

(213) 806-4351

Jeff Haberl

Energy Systems Lab

Department of Mechanical Engineering

Texas A\&M University

College Station, Texas 77843

(409) 845-6065

Martha Hewett

Director of Technical Projects

Center for Energy and

the Urban Environment

510 1st Ave. N., Suite 400

Minneapolis, Minnesota 55403-1609

(612) $348-4835$

Eric Hirst

Oak Ridge National Laboratory

Building $4500 \mathrm{~N}$, MS-6206

P.O. Box 2008

Oak Ridge, Tennessee 37331-6206

(615) 574-6304

Lynn K. Hobbie

Madison Gas \& Electric

Marketing Department

P.O. Box 1231

Madison, Wisconsin 53701-1231

(608) $252-4760$

Mark Hopkins

The Alliance to Save Energy

1725 K St., Suite 914

Washington, D.C. 20036

(202) 857-0666
Ken Keating

Bonneville Power Administration

Program Evaluation/Section RPEB

905 NE 11th Ave./P.O. Box 3621 - RMC

Portland, Oregon 97208-3621

(503) 230-3314

Betsy Krieg

Pacific Gas \& Electric

Research and Development

3400 Crow Canyon Rd.

San Ramon, California 94583

(510) 866-5318

Les Lambert

Lambert Engineering, Inc.

601 NW Harmon Blvd.

Bend, Oregon 97701

(503) 388-2623

Pierre H. Landry

Market Research and Evaluation

Southern California Edison

Room 391, G.O.1

P.O. Box 800

2244 Walnut Grove Ave.

Rosemead, California 91770

(818) 302-1826

Dennis Landsberg

The Fleming Group

6310 Fly Rd.

East Syracuse, New York 13057

(315) 437-1869

Ed Lovelace

Southern California Gas Co.

P.O. Box 3249, M.L. \#203A

Los Angeles, California 90051-1249

(213) 689-3882

Philip Mihlmester

Vice President

Applied Management Sciences, Inc.

Fairbanks Plaza

575 Oak Ridge Turnpike

Oak Ridge, Tennessee 37830

(615) 482-2721 
Bill Miller

Pacific Gas \& Electric

3400 Crow Canyon Rd.

San Ramon, California 94583

(510) $973-3031$

William R. Mixon

Manager, Existing Buildings Research

Energy Division

Oak Ridge National Laboratory

P.O. Box 2008, Bldg. 3147, MS-6070

Oak Ridge, Tennessee $37831-6070$

(615) 576-7323

Steven Nadel

American Council for an Energy-

Efficient Economy

1001 Connecticut Ave., NW

Suite 801

Washington, D.C. 20036

(202) 429-8873

\section{Sharon Noel}

Southern California Edison

P.O. Box 800

2244 Walnut Grove Ave.

Rosemead, Cálifornia 91770

(818) $302-3690$

Michael Parti

President

Applied Econometrics, Inc.

331 Ninth St.

Del Mar, California 92014

(619) 755-1266

H. Gil Peach

H. Gil Peach \& Associates

16232 N.W. Oak Hills Dr.

Beaverton, Oregon 97006

(503) 645-0716

Andy Perkins

Green Mountain Power

P.O. Box 850

South Burlington, Vermont 05402

(802) 864-5731
Frances J. Peterson

Marketing Manager for

Commercial Programs

Bonneville Power Administration

905 NE 11th Ave./ P.O. Box 3621 - RMC

Portland, Oregon 97208-3621

(503) $230-5860$

Eric Pulliam

San Diego Gas \& Electric

P.O. Box 1831

San Diego, California 92112

(619) 696-4723

Eric Rogers

Wisconsin Electric Power Co.

231 West Michigan A.ve.

Room P401

Milwaukee, Wisconsin 53201

(414) 221-2510

Jeffrey Schlegel

Wisconsin Energy Conservation Corp.

2158 Atwood Ave.

Madison, Wisconsin 53704

(608) 249-9322

Don Schultz

California Public Utilities Commission

1107 9th St., Suite \#7110

Sacramento, California 95814

(916) 324-5953

Dave Wolcott

New York State Energy Research

and Development Authority

2 Rockefeller Plaza

Albany, New York 12223

(518) $432-4630$

Roger L. Wright

President

RLW Analytics, Inc.

17389 Gehricke Rd.

Sonoma, California 95476

(707) $939-8823$ 


\section{REGULATORY-PRACTICES SURVEY PARTICIPANTS}

Michael Ambrosio

New Jersey Board of Public Utilities

Two Gateway Center

Newark, New Jersey 07102

(201) 648-2129

Dennis Bergeron

Maine Public Utility Commission

242 State St.

State House Station 18

Augusta, Maine 04333

(207) 289-3831

David Berry

Chief, Economics and Research

Arizona Corporation Commission

1200 West Washington St.

Phoenix, Arizona 85007

(602) 542-0742

Janet Besser

Utility Analyst

New Hampshire Public Utilities Commission

8 Old Suncook Rd.

Bldg. 1

Concord, New Hampshire 03301-5185

(603) 271-2431

Douglas Cowle

Maine Public Utility Commission

242 State St.

State House Station 18

Augusta, Maine 04333

(207) 289-3831

Martin E. J. Cummings

Energy Efficiency Project Director

State of New York

Public Service Commission

Department of Public Service

Three Empire State Plaza

Albany, New York 12223

(518) 474-1932
Phylicia Fauntleroy

District of Columbia Public Service Commission 450 5th St., NW

Washington, D.C. 20001

(202) 626-5147

Anita Fenischel

Maryland Public Service Commission

American Building

231 East Baltimore St.

Baltimore, Maryland 21202-3486

(301) 333-2878

Gene Heinze-Fry

Massachusetts Department of Public Utilities

100 Cambridge St.

Boston, Massachusetts 02202

(617) 727-9748

Tom Henderson

Nevada Public Service Commission

727 Fairview Dr.

Carson City, Nevada 89710

(702) 687-6048

J. Jenkins

Director of Electric and Gas Evaluations

Florida Public Service Commission

101 East Gaines St.

Fletcher Building

Tallahassee, Florida 32399-0850

(904) 488-8501

Connie Kolter

Senior Economic Analyst

Oregon Public Utilities Commission

300 Labor and Industries Building

Salem, Oregon 97310

(503) 378-6636

Martin Kushler

Michigan Public Service Commission

Mercantile Building

6545 Mercantile Way

P.O. Box 30221

Lansing, Michigan 48909

(517) 334-6431 
Linda Latham

Massachusetts Department of Public Utilities 100 Cambridge St.

Boston, Massachusetts 02202

(617) 727-9748

James McLawhorn

North Carolina Utilities Commission

430 North Salisbury St.

Dobbs Building

P.O. Box 29510

Raleigh, North Carolina 27626-0510

(919) 733-2267

Paul Newman

Assistant Administrator for Electric Policy

Public Service Commission of Wisconsin

477 Hill Farms State Office Building

Madison, Wisconsin 53707

(608) 267-5112

Anthony Polomski

New Jersey Board of Public Utilities

Two Gateway Center

Newark, New Jersey 07102

(201) 648-2129

Ralph Prahl

Coordinator of DSM Evaluation Research

Public Service Commission of Wisconsin

477 Hill Farms State Office Building

Madison, Wisconsin 53707

(608) 267-5112

Deborah Ross

Policy Specialist

Washington Utilities and

Transportation Commission

Chandler Plaza Building

1300 South Evergreen Park Dr., SW

Olympia, Washington 98504-8002

(206) 586-1186

Nathan Treadway

DSM Economist

Texas Public Utilities Commission

7800 Shoal Creek Blvd.

Suite $400 \mathrm{~N}$

Austin, Texas 78757

(512) 458-0100
Tony Visnesky

Senior Economist

Illinois Commerce Commission

Leland Building

527 East Capitol Ave.

P.O. Box 19280

Springfield, Illinois 62794-9280

(312) 524-0337

Rick Weston

Economist

Vermont Public Service Board

89 Main St.

City Center Building, Third Floor Montpelier, Vermont 05602

(802) 828-2358 


\section{Appendix B R\&D SURVEY FORM}

\section{CIEE TELEPHONE SURVEY QUESTIONNAIRE}

\section{Part 1: Survey Respondent Data}

Name

Title/Position

Organization

Address

Telephone

Fax

Area of impact-evaluation expertise:
Residential-retrofit
Residential-new
Commercial-retrofit
Commercial-new
Industrial
Agricultural

How many years of experience do you have in impact evaluation? 


\section{Part 2: Current Evaluation Practices (General Topics)}

First, we'd like your opinion about current DSM impact evaluation efforts:

1. Of the DSM impact evaluation efforts you know about, which ones, in your opinion, are "leading edge" or state-of-the-art (SOA)?

2. What characteristics do these programs have that make them SOA?

3. Can you provide a bibliographic citation for these evaluation studies? Copy of report?

4. Overall, how would you characterize the quality of DSM impact evaluation plans today? Why? 


\section{Part 3: Analysis Problems and Issues}

We want your opinion about what are the most important issues and challenging problems related to DSM impact evaluation analysis. In addition, we want your opinion about possible solutions to these problems, especially those that could be solved through R\&D. We are interested in solutions that: (a) identify new concepts and methods (not incremental improvements to existing techniques); and (b) could advance the state of the art.

We are interested in a number of problem areas such as:

1. Use of engineering analysis and engineering calculation methods.

2. Use of analysis methods for measured data.

3A. Experiment design, including methods to compare trade-offs between sample size, length of monitoring period, and accuracy of results (level of confidence).

3B. Sample size and sampling designs.

4. Cost of analysis for impact measurement. For example, determining how much money should be spent on monitoring and evaluation, and determining cost-effectiveness of impact evaluation.

5. Persistence of energy savings. 


\section{Part 4: Monitoring Hardware Problems and Issues}

We also want your opinion about what are the most important issues and challenging problems related to DSM impact evaluation monitoring hardware, as well as your opinion about possible solutions to these problems.

We are interested in a number of problem areas such as:

1. Innovations needed to improve metering technologies to better serve DSM impact evaluations; for example, nonintrusive metering.

2. Ways to reduce the cost of metering technologies for DSM impact evaluations; for example, inexpensive sensors and data loggers, or efficiency improvements in measurement plan design and hardware installation.

3. Ways to better process and analyze field-monitored data; for example, being able to work effectively with very large data sets. 


\section{Part 5: Evaluation of Specific DSM Measures and Technologies}

We also want your opinion about the problems and issues related to evaluating the impact of important DSM measures and technologies, and your ideas for possible solutions. We have five areas of concern: (a) estimating first year savings; (b) identifying/quantifying load shape changes; (c) evaluating rebound effects; (d) determining useful life of measures; and (e) determining persistence of energy savings.

In this context, we are primarily interested in the following measures (please think about the top three or four DSM technologies that are most difficult to evaluate in terms of energy savings):

1. Residential DSM measures, such as:
a. Efficient appliances
b. Evaporative coolers
c. Weatherization measures
d. Lighting

2. Commercial DSM measures, such as:
a . Lighting, including performance and comfort issues
b. HVAC, including interactive lighting effects
c. Miscellaneous measures

3. Industrial DSM measures, such as:
a. Lighting
b. HVAC, including interactive lighting effects
c. Miscellaneous measures

4. Agricultural DSM measures, such as:
a. Pumping improvements
b. Miscellaneous measures
c. Refrigeration 


\section{Part 6: Special and Cross-Cutting Issues and Problems}

Lastly, we want your opinion about problems and solutions for a number of special issues including:

1. Whole building vs. end-use impacts. For exc... ple:

a. Deternining end-use impacts from whole-building data.

b. Determining DSM program impact from whole-building data.

2. Methods to extrapolate individual building-level impacts to sector or regional impacts.

3. How have DSM incentives affected impact-evaluation methods? What are you doing differently as a result of incentives?

4. Certain fuel-type issues, such as whether or not fossil-fuel impacts should be measured if electric DSM measures affect consumption of other fuels.

5. How to evaluate the savings impacts of residential and commercial energy audit programs. 


\title{
Appendix C REGULATORY PRACTICES SURVEY FORM
}

\author{
Survey of Selected State Regulators \\ Issues for Measurement and Evaluation of DSM Impacts
}

State

Elec. LCP Status

Date

Respondent

Telephone Number
Position

Agency

\section{Regulatory Practice}

1. Does your state require an impact evaluation of DSM programs? (Interviewer will note that we are interested only in impact evaluations, not process or cost/benefit studies.)

No

Yes (Indicate type of evaluation),

2. Are stricter evaluation methods used when an incentive payment for conservation achievement is being considered?

No,

Yes,

3. Do you recommend or require impact evaluations of:

a. Energy audit or customer information programs

b. All full-scale DSM programs

c. Selected DSM programs, e.g.,

d. Pilot DSM programs 
e. Electric only

f. Gas only

g. By specific end-use, (such as)

4. Does the PSC have regulations or guidelines for, or give advice to, utilities on the best methods for performing DSM impact evaluations? (Obtain citation.)

No,

Yes,

5. Do regulators have authority to approve DSM impact evaluation plans by utilities? And, if so, which utilities' plans have been approved to date?

6. Are gas and electric utilities treated differently in terms of evaluation requirements or expectations?

No, Yes,

\section{Impact Evaluation Issues}

7. What DSM impact evaluation issues are PSC staff most interested in examining as part of a measurement and evaluation (M\&E) effort?

\section{METHODOLOGY}

a. Technical methods to determine conservation achievement $(\mathrm{kW}, \mathrm{kWh})$ 
b. Sampling techniques

c. Experimental design such as control group studies

d. Length or timing of metering period

e. Accuracy of results, level of confidence

f. Support for improved marginal cost calculation for natural gas

g. Other

PARAMETERS

a. Useful life of DSM measure

b. Persistence of energy savings

c. First-year savings $(\mathrm{kW}, \mathrm{kWh})$

d. "Snapback" effect

e. Load-shape changes

f. Other

8. What techniques are employed or considered satisfactory (circle one) in preparing a DSM impact evaluation?

a. Billing-data analysis

b. Engineering estimates or calculations, including simulation models

c. Statistical methods, such as Conditional Demand Analysis

d. End-use monitoring

e. Case studies of technology assessments

f. Hybrid methods, e.g.

g. Savings estimates from other jurisdictions

h. Savings calculated using data from other jurisdictions 
9. Have you found any specific DSM, or conservation measures, particularly difficult to measure for energy savings?

No, Yes,

10. Are you satisfied with the quality and thoroughness of evaluation of DSM programs to date? No (What problems do you see/have?),

Yes,

11. What problems have you solved in evaluation methods which have improved the quality of impact evaluation results?

12. Do you encourage utility R\&D to solve impact-evaluation problems? No,

Yes, some examples are

13. What improvements in evaluation, impact or otherwise, would you like to see?

a. Timeliness of results

b. Accuracy

c. Other 


\title{
Appendix D \\ REGULATORY PRACTICES SUMMARY
}

\author{
REPORT OF THE SURVEY OF STATE REGULATORS \\ CONCERNING ISSUES FOR MEASUREMENT \\ AND EVALUATION OF DSM PROGRAM IMPACTS
}

\begin{abstract}
State regulatory agencies have been the driving force in DSM program planning, implementation, and evaluation as part of activity involved in least-cost planning (LCP). The evolution of DSM program planning and evaluation is largely the result of regulatory staff asking for more and more research and analysis of DSM program results. We interviewed staff from regulatory agencies in 19 states that are known to be active in least-cost utility planning (Hopkins 1990). Interviews were conducted in person and by telephone during March and April 1991. Respondents in each agency are responsible for review and evaluation of utility DSM programs for both electric and natural-gas programs. All states included in the survey have LCP practices in effect for electric utilities, and nine of these states also have recently initiated gas activity in LCP. A total of 23 regulatory agency staff members were interviewed. The questionnaire used to guide the interviews contained 13 questions covering three topic areas: regulatory practices, impact evaluation issues, and recommendations for improvement. This appendix summarizes each interview.
\end{abstract}

Interviews include data on the following topics:

- Specific requirements for DSM program impact evaluation.

- The level of impact evaluation used when incentives for conservation achievement are being considered.

- Categories of DSM programs by requirement of evaluation.
- Public Service Commission (PSC) regulations, guidelines, or advice to utilities on the best methods for performing DSM impact evaluations.

- Regulatory authority to approve DSM impact evaluation plans by utilities.

- Specific utility plans approved to date.

- Differences in regulatory treatment in gas and electric evaluation requirements or expectations.

- Priorities in DSM impact evaluation issues identified by staff as most important to examine as part of an M\&E effort.

- Techniques used by utilities, and considered satisfactory by regulators, in preparing a DSM impact evaluation.

- Specific DSM or conservation measures that have been found to be particularly difficult to measure for energy savings.

- Regulator satisfaction with the quality and thoroughness of evaluation to date.

- Problems solved in evaluation methods that have improved the quality of impact evaluation results.

- Utility R\&D efforts to solve impact evaluation problems.

- Improvements in evaluation sought by regulator: 
Seven of the 19 states in which we conducted interviews have formal requirements in place for DSM program impact evaluation. These states require such evaluation for all full-scale DSM programs and for most pilot programs. (See Table D-1.) Of the 13 states without formal requirements, six include impact evaluation in the usual and customary review of DSM program plans, or in rate cases. The remaining seven states all recommend that impact evaluation be done for DSM programs, and several of these expect requirements in the near future. Nearly all of the respondents indicated that their states have impact evaluation require- ments or recommendations in effect for DSM programs. Evaluation is most frequently recommended for full-scale and pilot electric DSM programs. Only three states indicated that they recommend a separate impact evaluation for energy audits or customer information programs. There are no explicit methodologies set out by the regulators in any of the 19 states, although 10 states reported that evaluation guidelines, which include objectives for evaluation, were available to utilities. Many state regulatory staff regularly advise utilities on the best methods for performing DSM impact evaluations.

Table D-1. Status of Regulatory Requirements for DSM Program Impact Evaluation and Incidence of Stricter Requirements for Conservation Achievement Incentive Payments

\begin{tabular}{|c|c|c|l|c|c|l||}
\hline \multirow{2}{*}{ State } & \multicolumn{3}{|c|}{ Impact Evaluation Required } & \multicolumn{3}{c|}{ Stricter Evaluation for Incentives } \\
\cline { 2 - 8 } & No & Yes & \multicolumn{1}{|c|}{ Notes } & No & Yes & \multicolumn{1}{|c|}{ Notes } \\
\hline AZ & $\mathrm{X}$ & & Not now & $\mathrm{X}$ & & No incentives \\
\hline CT & $\mathrm{X}$ & & In practice & $\mathrm{X}$ & & No incentives \\
\hline DC & & $\mathrm{X}$ & Impact required & $\mathrm{X}$ & & No incentives now \\
\hline FL & $\mathrm{X}$ & & No, program and process only & $\mathrm{X}$ & & \\
\hline IL & $\mathrm{X}$ & & No full-scale programs & $\mathrm{X}$ & & No incentives \\
\hline MA & & $\mathrm{X}$ & With basic monitoring & & $\mathrm{X}$ & Incentives in place \\
\hline MD & $\mathrm{X}$ & & Recommended & & $\mathrm{X}$ & \\
\hline MI & $\mathrm{X}$ & & Not required per program & & $\mathrm{X}$ & More documentation \\
\hline ME & $\mathrm{X}$ & & Not specified & & $\mathrm{X}$ & More control groups \\
\hline NC & $\mathrm{X}$ & & & $\mathrm{X}$ & & No incentives now \\
\hline NH & & $\mathrm{X}$ & Actual results & & $\mathrm{X}$ & Case by case \\
\hline NJ & $\mathrm{X}$ & & Rate cases and proposed & $\mathrm{X}$ & & Also proposed \\
\hline NV & & $\mathrm{X}$ & Using combo methods & $\mathrm{X}$ & & Current docket open \\
\hline NY & & $\mathrm{X}$ & Process and impact evaluation & $\mathrm{X}$ & & All get incentives \\
\hline OR & $\mathrm{X}$ & & Case by case & & $\mathrm{X}$ & In "save" program \\
\hline TX & $\mathrm{X}$ & & Participants and kW/kWh & $\mathrm{X}$ & & \\
\hline VT & $\mathrm{X}$ & & Not now, but will be & $\mathrm{X}$ & & Possibly \\
\hline WA & $\mathrm{X}$ & & Not at this time & $\mathrm{X}$ & & After June 30 \\
\hline WI & & $\mathrm{X}$ & Impact sometimes included & $\mathrm{X}$ & & Staff not convinced \\
\hline
\end{tabular}


Respondents were asked if a series of techniques commonly used in preparing DSM impact evaluations were used by utilities in their state and, if so, if they considered the use satisfactory. The most frequently cited technique is billingdata analysis, used satisfactorily by utilities in 18 of the 19 states. The technique eliciting the most positive responses from regulators is end-use monitoring. In use by utilities in $\mathbf{1 5}$ of the 19 states, nearly all indicated that they wanted to see more end-use metering studies using well-designed control groups. The high cost of metering forces a trade-off between accuracy and expense for many utilities. The high cost of monitoring has led to a call for evaluation studies to be transferable to other utilities in the state. Engineering estimates or calculations, including simulation models, are used in 18 of the 19 states but are considered unsatisfactory by regulators in five states. Critics of the engineering estimates complain that such estimates are better for DSM program design than for evaluation, and one commented that engineering estimates tend to overestimate conservation potential. The least popular evaluation technique with state commission staff is savings estimates from other jurisdictions, and where it is considered satisfactory by regulators, this is only true in the absence of more reliable data.

All respondents queried told us that they expected evaluation of DSM programs to improve. A majority of respondents, 15 of the 19 states, reported being unsatisfied with the quality and thoroughness of evaluation programs to date. Regulators seek to raise the level of sophistication in DSM impact evaluation. Four of the states reported that they were just beginning to develop evaluation plans and that it was too early to project improvements. Regulators from 15 other states offered a variety of suggestions for improvements. All improvements would increase the accuracy and level of confidence in DSM evaluation and would increase accountability for DSM expenses. Several regulators cited the need for more professionally trained evaluators.

Clearly, impact evaluation of DSM programs is a growth industry in states with active leastcost utility planning initiatives. Regulators are raising the level of sophistication in impact evaluation in asking for more accountability of conservation achievement as a result of DSM programs. More DSM program evaluators, better DSM program design and implementation, and more accurate results are sought by nearly all regulators interviewed. Regulators are calling for more investment in DSM program evaluation by utilities and more attention from regulators. The issue is expected to become more important as incentives for conservation achievement are considered.

\section{REGULATORY PRACTICES SUMMARY}

\section{Arizona}

Impact evaluations are recommended, but not required, in Arizona at this time. Societal and total resource cost tests are used to evaluate all DSM programs in a utility cost recovery application. No shareholders' incentives for conservation achievement are used. The Arizona Corporation Commission (ACC) staff recommends that electric utilities perform impact evaluations of all full-scale and pilot DSM programs. The staff has recommended evaluation of specific conservation measures in certain cases; for example, using a sample group of participants and engineering estimates or end-use metering.

The staff is willing to advise utilities on the best methods for performing impact evaluations of DSM programs, although no formal guidelines exist at this time. The staff expects to spend more time with smaller utilities, especially in cases where the Commission has ordered specific DSM programs to be implemented. The Commission has the authority to approve DSM impact evaluation plans by utilities but has not approved a plan to date. A decision by the Commission is currently pending on hearings held in November and December 1990, concerning the least-cost plan prepared by Arizona Public Service Co. (AZPSCO). 
Gas utilities are not required, or expected, to develop evaluation plans at this time.

The ACC staff is most interested in examining control-group studies as part of an M\&E plan. Other issues of interest to staff include persistence of energy savings, "snapback" effects, and load-shape changes. The staff expects to examine costs associated with DSM measures. Utilities must now include customer capital and maintenance costs for DSM measures.

The staff reports no practical experience with impact evaluation. However, engineering estimates and end-use models are being used in a "before-and-after" study using whole-house meters. Participants in the project include the ACC staff, the Arizona Energy Office, and AZPSCO. The project is funded by AZPSCO. Meters were installed in fall 1989, DSM measures were applied during 1990, and data collection is scheduled for summer 1991.

Except for the effect of evaporative transpiration from trees, the staff has not found any specific DSM or conservation measures parti $u$ larly difficult to measure for energy savin $_{0}$ s. The staff declined to comment on the quality and thoroughness of DSM program evaluation to date, citing a lack of completed evaluations so far. The staff has encouraged utility $R \& D$ to solve impact-evaluation problems in maintenance of data collected and reported, but this is limited to the current joint study with AZPSCO.

As for improvements in evaluation, impact or otherwise, the staff would like to see larger samples of metered control groups.

\section{Contact: Mr. David Berry}

Chief, Economics and Research Arizona Corporation Commission (602) 542-0742

\section{Connecticut}

Impact evaluation of DSM programs is widely practiced in Connecticut, although not required by legislation or regulation. Incentive payments for conservation achievement have not been requested by utilities. Impact evaluations are done for all full-scale and pilot DSM programs, for both electric and natural-gas programs.

Guidelines on the best methods for performing DSM impact evaluations are found in the Department of Public Utilities' (DPU's) decisions. DPU staff advises utility staff in this area as part of the collaborative group discussions currently taking place. The collaborative discussions include participation from DPU staff, utilities, and consumer groups in developing utility DSM programs in Connecticut.

The DPU has the authority to approve impact evaluation plans in Connecticut, and to date plans have been approved for Connecticut Natural Gas Co., Connecticut Light \& Power Co., and United Illuminating Co. Electric companies are reported to be treated differently because of the magnitude of electricity sales relative to gas sales and the larger budget amount of the electric DSM programs. Additionally, electric companies use professional evaluators to measure the effects of DSM programs.

The DPU staff is reported to be most interested in examining accuracy of results and technical methods to determine conservation achievement as part of an M\&E effort. Additionally, the staff is interested in improved marginal cost calculations for natural gas, specific loadshape changes for electricity, and process evaluations of DSM program delivery systems.

Techniques used in preparing a DSM impact evaluation include billing-data analysis; enduse monitoring; and, for pilot programis, case studies of technology assessments. Engineering estimates or calculations, including simulation models, are thought to be better for DSM program design than for evaluation. Specific DSM or conservation measures found to be particularly difficult to measure for energy savings in- 
clude residential-housing rehabilitation, total-building retrofits, education programs, lowcost/no-cost weatherization measures, and the interactive effect of several conservation measures.

DPU staff is dissatisfied with the quality and thoroughness of evaluation of DSM programs to date. Electric utilities seem more concerned with the cost of evaluation efforts than with conservation achieved, and gas utilities have not fielded enough programs to provide any substantial material for evaluation. Progress is reported in development of avoided-cost calculations and in understanding which data points are available for measurement and which are not. DPU staff does not actively encourage utility $R \& D$ to solve impact-evaluation problems.

The success of many DSM programs is often dependent on behavioral aspects of energy consumption. Current use of economic and engineering calculations necessarily leaves out the behavioral aspects. The DPU staff would like to see the inclusion of more sociological elements in the evaluation of DSM programs.

Contact: Mr. Wayne Estey

Connecticut DPU

(203) 827-1553

\section{District of Columbia}

Impact evaluations of DSM programs are required for both gas and electric utilities in the District of Columbia. The PSC has instructed the collaborative working group to review utility development of impact-evaluation issues. Evaluation methods are developed for each program. Currently, incentive payments to the utilities for conservation achievement are not available in the District of Columbia. However, the Commission has allowed for that possibility for successful electric programs.

Impact evaluation is required for al: DSM programs, including energy surveys, and customerinformation programs and for all full-scale and pilot DSM programs. Advice on the best meth- ods for performing impact evaluations has its source in the proposed regulations for LCP programs developed by the Commission. The proposed regulations contain evaluation objectives. PSC staff gives advice to utilities through their participation in the collaborative working groups. The PSC has the authority to approve DSM impact evaluation plans by the utilities as part of the LCP process. To date, no utility plans have been approved. Both utilities in the District of Columbia have submitted least-cost plans that are currently under review. The gas utility and the electric utility are not treated differently in terms of requirements or expectations.

The PSC staff reported all impact evaluation issues listed to be equally important in their review of evaluation plans by the utilities. These include technical methods to determine conservation achievement; sampling techniques; experimental design, such as controlgroup studies; length or timing of metering periods; accuracy of and level of confidence in results; and support for improved marginal cost calculation for natural gas. Parameters of an evaluation study, such as the useful life of a DSM program, persistence of energy savings, the first-year savings, the "snapback" effect, and load-shape changes, were also found to be important. However, the relative importance of each criterion depends on the measure and the program delivery.

Evaluations of DSM programs have not been fully completed. Billing data may be used for evaluation, but it is not compiled for that purpose. Engineering estimates of consumption are used by utilities, along with statistical methods such as CDA. The PSC staff reports some reservations about the ability of end-use monitoring to measure electric impacts directly. Case studies of technology assessments are used by the utilities; hybrid methods of analysis are often worked out in the collaborative working groups. Both utilities use savings estimates from other jurisdictions, but it is not generally accepted by the PSC because it is not thought to be relevant to the District of Columbia. 
The staff has found several DSM measures particularly difficult to measure: energy surveys (audits), residential compact fluorescent light bulbs, residential building rehabilitation, and DSM in master-metered, multifamily buildings. The staff had no comment on the quality and thoroughness of DSM programs to date, citing not enough evaluation results to judge. PSC staff encourages utility R\&D by the gas utility to solve impact evaluation problems. For example, R\&D to improve DSM impact estimates for use in the integrated planning model is currently in progress. Most of the development of the current natural-gas computer model is stateof-the-art. The model is used to calculate equilibrium levels in demand and supply resource integration. On the electric side, R\&D encouragement for evaluation is found in the collaborative working-group discussions.

The staff would like to see improvements in two areas: for electricity, more process evaluations; for natural gas, more use of econometric methods.

\section{Contact: Dr. Phylicia Fauntleroy District of Columbia PSC (202) 626-5147}

\section{Florida}

The Florida PSC does not require an impact evaluation of DSM programs that measures conservation achievement. The PSC does require program cost-effectiveness and process evaluation for DSM programs. Incentives for conservation achievement are measured in the same fashion as other programs. All full-scale DSM programs are evaluated, including energy audit and customer information programs. Pilot programs are given a lesser review. Evaluations are made primarily for electric DSM programs. Gas DSM programs are judged as to their benefit to electric load reduction, not natural-gas efficiency.

The PSC has regulations (Rule Chapter 25-17, FL Administrative Code) that include objectives for DSM program evaluation. Regulators in Florida have the authority to review evaluation plans that may or may not include plans for impact evaluations. In general, all investorowned and large municipal and cooperative electric utilities have had plans approved. One large natural-gas utility has an approved general evaluation plan. Other smaller gas utilities have chosen to follow the plan of the largest gas utility. Gas and electric utilities receive different treatment in terms of evaluation requirements because: the benefits of the respective DSM programs are different. The purpose of the gas programs is to increase gas market share and thereby reduce electric load.

The PSC staff is most interested in examining the effect of free riders, the effect of lost revenue from conservation, measurement costs as part of an M\&E effort, load-shape changes, and externalities. Techniques used in preparing a DSM impact evaluation are limited to billingdata analysis to obtain household consumption per customer over time and end-use monitoring using submetered control groups. Engineering simulation models have been used by utilities in the past, but the PSC staff was not satisfied because the simulations did not include data on the behavioral variables of specific appliances. Weather is too different in Florida to use savings estimates from other jurisdictions. Only one DSM measure, customer information programs, has been found particularly difficult to measure for energy savings.

The PSC staff is reported to be generally satisfied with the quality and thoroughness of DSM program evaluation to date. More could be done by utilities, but that is not thought to be costeffective. The staff has solved a few evaluation problems, which improved the quality of evaluation results. These include substituting computer modeling for end-use meter sampling in the residential market. The staff has found the commercial market to be less homogeneous and more difficult to understand.

Utilities are not specifically encouraged to conduct R\&D to solve impact-evaluation problems. The staff would like to see less utility involvement in conservation programs and more 
reliance on time-of-day pricing and radiocontrolled service interruptions.

$\begin{array}{ll}\text { Contact: } & \text { Mr. J. Jenkins } \\ & \text { Director of Electric and Gas } \\ & \text { Evaluations } \\ & \text { Florida PSC } \\ & \text { (904) 488-8501 }\end{array}$

\section{Illinois}

The Illinois Commerce Commission (ICC) does not require impact evaluations of full-scale DSM programs. Instead, the Commission requires that each utility submit a biennial evaluation plan to include estimates of market penetration but not conservation achievement. There are no incentive payments for conservation achievement in Illinois. Impact evaluations are recommended by ICC staff for both electric and gas utilities to measure $\mathrm{kWh}$ and therm savings from pilot programs. Billingdata analysis is the usual technique used to prepare this calculation. The ICC staff generally does not advise the utilities on the best methods for performing DSM impact evaluations. Best methods are determined by the utility staff.

Regulators in Illinois have the authority to review, but not to approve, DSM impact-evaluation plans by utilities. Such authority has not been requested. Currently, an evaluation plan submitted by Commonwealth Edison Co. is under review. Utilities do not receive different regulatory treatment due to fuel type; rather, each utility is treated separately. Each case is compared to a conservation target estimated in 1983.

Impact-evaluation issues of most interest to ICC staff are technical methods to determine conservation achievement; accuracy of results; support for improved marginal cost calculation for natural gas; properly capturing capacity; sampling techniques; and experimental designs, such as control-group studies. Parameters of an M\&E effort most interesting to ICC staff are useful life of the DSM measure, persistence of energy savings, load-shape changes, "snapback" effect, and first-year savings.

Techniques used and considered satisfactory by the staff are limited to billing-data analysis, hybrid methods, and savings estimates from other jurisdictions with similar characteristics. Their experience with engineering estimates is that these tend to overestimate conservation potential. They have not used end-use monitoring because of the high cost but indicate that such expenses are justifiable in some cases. Energy savings have been particularly difficult to measure for a residential water-heater blanket-wrap program because of the difficulty in measuring free riders.

Regulators are dissatisfied with the quality and thoroughness of evaluation of DSM programs to date. There is a dearth of analytical ability in evaluating DSM programs by utilities. Most evaluators, including utilities, regulators, and third parties, are thought to be predisposed to a particular point of view. The staff understands that problems such as freerider measurement and interactive effects exist, but it has not yet had the opportunity to solve them.

The ICC staff generally encourages utilities to solve R\&D impact-evaluation problems. For example, cost recovery has been approved for Commonwealth Edison to retain Battelle/Pacific Northwest Labs to evaluate pilot DSM programs. The staff would like to see improvements in analytical skills, greater use of consulting evaluators, and more experimentation with alternative methodologies.

Contact: Mr. Tony Visnesky

Senior Economist

Illinois Commerce Commission

(312) 524-0337

\section{Maine}

The Maine PUC requires evaluation of DSM programs, but impact evaluation per se is not specified. However, impact evaluation is ex- 
pected to be a minimum requirement in any evaluation of program cost-effectiveness. Evaluation methods are required when an incentive payment for conservation is being considered. For example, incentive-award program evaluation requires a control-group study for residential conservation programs. Evaluations are required for all electric full-scale and pilot DSM programs. There are no gas DSM programs in Maine. Only about $10 \%$ of Maine households get natural gas, and there is only one naturalgas distribution company.

The PUC has prepared guidelines on DSM program planning and evaluation that include a list of evaluation objectives. Regulators in Maine have the authority to approve DSM impact-evaluation plans by electric utilities but have not exercised it. No DSM programs have been filed with the PUC recently. Impactevaluation issues of most interest to the PUC staff as part of the M\&E effort are technical methods to determine conservation achievement; experimental design, such as controlgroup studies; and accuracy of results and level of confidence. Impact-evaluation parameters such as useful life, persistence, and first-year savings of a DSM measure are also of interest. Load-shape changes are also important, but not "snapback" effect.

Utilities in Maine use a variety of techniques to prepare a DSM impact evaluation. No individual measure used exclusively is considered satisfactory by regulators. Utilities use billingdata analysis, engineering estimates, statistical methods, and end-use monitoring in a hybrid methodology. The staff has found one DSM or conservation measure particularly difficult to measure for energy savings: economizers, which are used to introduce outside air to commercial refrigeration equipment. This is because they are influenced by heating-degreeday calculations and require wet bulb/dry bulb analysis.

Regulators are not satisfied with the quality and thoroughness of evaluation of DSM programs to date. Utilities have problems with poor evaluation planning. For example, better planning would include data collection, man- agement implementation and data analysis plans, a list of control factors, interactive effects, and statistical design issues. The staff has not yet solved problems to improve evaluation results. However, it is trying to bring evaluation practices up to a higher standard. The staff is planning a workshop on evaluation for the largest electric utility.

Utility R\&D to solve impact-evaluation problems is mildly encouraged. The PUC recently allowed cost recovery for Central Maine Power Co. to join the EPRI, and all utilities provide load research in small-sample metering. The staff would like to see improvements in evaluation as a result of much better planning, more detail in task plans, and more scientific and economic analytical rigor.

\section{Contacts: Mr. Dennis Bergeron \\ Mr. Douglas Cowle \\ Maine PUC \\ (207) 289-3831}

\section{Maryland}

Impact evaluations for DSM programs are recommended by the Maryland PSC. More rigorous evaluation methods are used when an incentive payment for conservation achievement is being considered. Impact evaluations are recommended for all electric full-scale and pilot DSM programs. Evaluation of gas programs has not been requested.

The PSC has prepared general guidelines on evaluation as part of the long-range planning objectives for utilities. Regulators in Maryland do not have the authority to approve DSM impact-evaluation plans by utilities; rather, utilities receive approval of individual DSM program plans. To date, this has included only electric DSM programs.

The staff indicated a number of DSM impactevaluation issues as most interesting to examine as part of an M\&E effort. These include technical methods to determine conservation achievement; sampling techniques; experimental de- 
sign, such as selection of control groups; accuracy of results and level of confidence; and support for improved marginal cost calculation for natural gas. Additionally, the staff noted persistence of energy savings, "snapback" effect, and load-shape changes.

The most frequently used technique in preparing a DSM impact evaluation is engineering estimates or calculations (including simulation models). This is followed by billing-data analysis, statistical methods, end-use monitoring, case studies of technology assessments, hybrid methods, and savings calculated using data from other jurisdictions. Use of these techniques is considered satisfactory by regulators. Two DSM measures have been found to be particularly difficult to measure for energy savings: residential low-cost weatherization and compact fluorescent light bulbs.

Regulators are not satisfied with the quality and thoroughness of evaluation of DSM programs to date. Programs are often started before evaluation plans have been developed. The PSC recently asked utilities to submit evaluation plans within the first few months of program implementation.

Utilities have not requested cost recovery for any R\&D expenses to solve impact evaluation problems. The PSC staff would like to see improvements in DSM evaluation planning, such as more detailed evaluation plans in place as programs are being implemented, and process evaluation.

Contact: Ms. Anita Fenischel

Maryland PSC

(301) $333-2878$

\section{Massachusetts}

Impact evaluations are required as part of any DPU order on electric or gas DSM programs and for any DSM program linked to a request for an incentive award for conservation achievement. All residential full-scale and pilot DSM programs are included in these requirements.
Energy audit and customer information programs are more difficult to measure for energy savings; consequently, the staff is reluctant to recommend approval of some customer information programs. The staff is most interested in evaluating differences in capacity and energy as a result of a DSM program. Load-shape curves and end-use meters are the most common indicators of capacity on the plectric side, and end-use meters are planned thr some gas programs as well. Energy consumption is most often measured using billing-data analysis, as well as engineering estimates and on-off radio controls for air conditioning and water heaters.

The DPU staff refers to a series of orders that have advised the best methods for performing impact evaluations on electric DSM programs. Informal discussion allows DPU and utility staff members to review utility evaluation plans and comment on alternative approaches. Guidelines on impact-evaluation objectives for incentive consideration have been prepared.

The DPU has the authority to approve DSM impact-evaluation plans by utilities. To date, plans for Massachusetts Electric, Commonwealth Edison, Cambridge, and Western Massachusetts Electric have been approved. The staff is now working on the review of the Boston Edison Plan. On the gas side, the staff is now involved in a collaborative process with Boston Gas Co. as the company prepares its first plan.

On the electric side, the staff is most interested in examining $M \& E$ issues, prioritized as follows: accuracy of results, technical methods to determine conservation achievement, controlgroup studies, length or timing of metering studies, sampling techniques, and cost of evaluation. Issues on the gas side are listed with technical methods at the top, followed by statistical validity and load-shape changes (decrement profile). First-year savings, useful life, and persistence of DSM measure were expected for both electric and gas evaluations. On the electric side, load-shape change was also included. On the gas side, the final parameter was "snapback" effect. This was thought to be 
least interesting for electric evaluations because it would be too small to measure.

Techniques used by utilities in preparing a DSM impact evaluation, and considered satisfactory by regulators, include billing-data analyses, end-use monitoring, hybrid methods, and savings estimated from other jurisdictions. Engineering estimates, including simulation models, are thought to be more appropriate for program design purposes than for evaluation. End-use monitoring was described as having trade-offs between cost and accuracy.

DSM measures found to be particularly difficult to measure for energy savings are electric residential compact fluorescent light bulbs and the interactive effect of different gas measures applied to a single end-use, such as heating.

In terms of staff satisfaction with the quality and thoroughness of the evaluation of DSM programs to date, no gas company evaluations have been completed. The staff is generally satisfied with the development of electric evaluation but would like to see utilities continue to increase their level of sophistication. The quality of electric DSM program evaluation results has been improved using actual data from metering studies encouraging use of load-shape curves based on end-use metering (as a compromise between the high cost of metering and the desire for accuracy in results) and using Model-Based Statistical Sampling, which combines end-use metering and engineering estimates for sampling and statistical significance.

The staff generally encourages utility $R \& D$ to solve impact-evaluation problems in the development of technical methods to determine conservation achievement and in the work by gas utilities as part of end-use load research. It is too early in the process to suggest improvements in gas evaluation. The staff indicated improvements it would like to see in electric evaluations: reduced cost of end-use meters, better baseline construction practices for new construction, and research to investigate whether anything other than random changes exist in end-use data from different locations.

\author{
Contacts: Mr. Gene Heinze-Fry \\ Ms. Linda Latham \\ Massachusetts DPU \\ (617) 727-9748
}

\section{Michigan}

Energy conservation plans are prepared by electric utilities and filed with the Michigan PSC every two years. These include program evaluation plans but not necessarily impact evaluation of conservation achievement. There is no requirement to prepare an impact evaluation plan per DSM program. More documentation and closer scrutiny are applied to evaluation methods used by a utility when an incentive payment for conservation is being considered. Impact evaluations are recommended for all full-scale and selected DSM programs for both electric and natural-gas utilities.

PSC staff is available to advise utilities on the best methods for performing DSM impact evaluations during informal meetings and as part of review and mark-up of company plans. Regulatory authority to approve DSM impact evaluation plans by utilities has never been tested in Michigan. The staff presumes that any approval authority is in the context of conservation plans but is not explicitly stated to include impact evaluation plans. Historically, gas and electric utilities have not been treated differently; activity is focused more on electric DSM than on gas (for example, there is much discussion of electric DSM incentives). Prototypical incentives are now in place, but they are limited to a small conservation plan. An order published May 7, 1991, includes an inceritives package for Consumers Power $\mathrm{Co}$.

PSC staff is reported to be most interested in examining the following issues as part of an $M \& E$ effort: technical methods to determine conservation achievement, accuracy of results and level of confidence, and experimental design (control-group studies). Sampling techniques and length or timing of metering period were also listed but were of low priority. Parameters expected in an $y^{\prime}$ impact evaluation 
include useful life and persistence of energy savings, first-year savings, and load-shape changes. "Snapback" effect elicited the least staff interest. Current techniques used by utilities and considered satisfactory by regulators are billing-data analysis and end-use monitoring. Engineering estimates are used and are sometimes satisfactory, as are case studies of technology assessments. Savings estimates from other jurisdictions are sometimes used as inputs to the engineering calculations but are not considered sufficient on their own. Utilities do not use statistical methods, but the staff reports that they might be satisfactory. The DSM measure found to be most difficult to measure for energy savings is the interactive effects of lighting in commercial HVAC systems.

The staff is not satisfied with the quality and thoroughness of evaluation of DSM programs to date. Utilities have problems with the low level of effort and investment in DSM. The staff is noticing a little more activity on the part of the gas utilities than electric. Evaluation is starting to improve as a result of more regulatory pressure to make more extensive use of DSM programs. For example, Consumers Power Co. has recently proposed end-use metering to improve the quality of impact-evaluation results.

Utility R\&D to solve impact-evaluation problems is formally endorsed by the PSC. Michigan Rule No. 8528, which requires the DSM plans, stipulates that the Conservation Planning process be set up to incorporate a research and evaluation component. Activity takes place informally through staff and utility discussions, and formally they have encouraged utilities to invest in DSM technologies. The PSC staff believes that many state regulators and utilities jump into impact evaluation before adequately focusing on process evaluation. Specifically, when major new conservation programs are launched, several years of program development and improvement are often necessary before investing in impact evaluation.

The staff would like to see improvements in evaluation that would incorporate metering to improve billing analysis, especially in controlgroup studies.

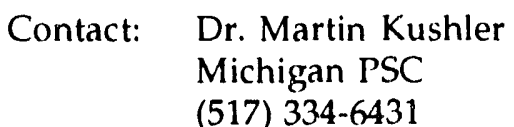

Nevada

Impact evaluation of DSM programs is practiced in Nevada by both gas and electric utilities, although it is not a specific requirement of the Nevada PSC at this time. A combination of engineering estimates, end-use meters, and bill analysis is used to develop an estimate of conservation savings. There is a current open docket on incentives for DSM programs for gas and electric utilities (Docket No. 89-651). Currently, an evaluation that includes an assessment of the effect of the DSM program on load shape is required for all full-scale and pilot DSM programs. A less rigorous evaluation is required for energy audits and customer information programs. Language is not as explicit for natural-gas programs. There is a requirement (NAC 881 \& 88111) that companies demonstrate in advance the energy-savings potential of a full-scale program through a pilot.

The PSC staff advises utilities on the best methods for performing DSM evaluations through workshops and informal discussions with utility staff. Regulators in Nevada have the authority to approve DSM impact evaluation plans by utilities. To date, plans have been approved for Sierra Pacific Power Co. and Nevada Power Co. in conjunction with electric LCPs. Southwest Gas Co. submitted an LCP that was rejected by PSC staff due to poor DSM planning. Nevada does not have a history of natural-gas regulation of DSM program activity. However, there is not likely to be any difference in regulatory treatment in approving DSM gas-program plans. The PSC staff is likely to agree with Southwest Gas in support for fuel switching. If the DSM plans are not considered to have improved, the PSC may prohibit the inclusion of fuel-switching as a resource-planning option. 
Several DSM impact-evaluation issues are of great interest to the PSC as part of an M\&E effort. The measurement of free riders is of primary interest. Staff is also interested in how to optimize the budget in evaluation. They would like to see if the cost of collecting incremental data is cost-effective. Additionally, they are interested in the persistence of energy savings for measures such as commercial high-efficiency lighting. The staff also raised the question: are costs associated with end-use metering without substantial DSM worthwhile? The staff believes that numerous estimates are available on a number of appliance end-uses. End-use metering should serve programs with high DSM potential. For example, Sierra Pacific spent over $\$ 1$ million for a five-year metering study. There is currently no end-use metering research by natural gas utilities.

Techniques used by electric utilities and considered satisfactory by regulators in preparing a DSM program include billing data analysis, engineering estimates or calculations, statistical methods, end-use monitoring, case studies of technology assessments, hybrid methods, and savings estimates from other jurisdictions. Gas utilities have not yet put evaluation procedures in place.

Energy savings have been found particularly difficult to measure for air-conditioning loadcontrol programs. In fact, Sierra Pacific Power Co. is still uncertain as to how many $k W h$ are being saved in air-conditioning loads. Other difficult-to-measure programs include customer education programs (such as workshops). The staff indicates that there is not yet enough experience with gas DSM programs to identify difficulties between DSM measures. They have also found residential envelope retrofit programs to be more difficult to measure than equipment retrofits because of the behavioral variance of cccupants.

The PSC staff reports it is generally satisfied with the quality and thoroughness of evaluation of DSM programs to date. The PSC will require a more rigorous accounting of lost revenues when the new rule goes into effect.
End-use metering has proven the most useful way to improve impact evaluation results so far. For example, at Sierra Pacific Power, enduse metering has been used for a wide range of residential and commercial DSM measures.

PSC staff encourages utility R\&D to solve impact-evaluation problems. However, R\&D can be used to delay or stall the implementation of programs that have already proven cost-effective in similar jurisdictions. PSC staff will support utility R\&D as long as it does not impede progress that would be made in the absence of the $R \& D$ investment.

Staff commented that improvements in evaluation were too difficult to project because "impact evaluation will always be estimates."

\section{Contact: Mr. Tom Henderson \\ Nevada PSC \\ (702) 687-6048}

\section{New Hampshire}

The New Hampshire PUC requires that utilities file reports of actual results of DSM programs. More rigorous evaluation methods are used when an incentive payment for conservation achievement is being considered (this is done in a separate rate case). Impact evaluations are required for all electric full-scale DSM programs and for pilot programs for which cost recovery is requested. Gas utilities have not developed any conservation programs to date.

The PUC staff does not consider itself knowledgeable enough on evaluation methodologies to advise utilities on the best methods for performing impact evaluations. There are no directives from the PUC. Regulators have not asked for, and currently do not have, authority to approve DSM impact evaluation plans by utilities. To date, only Granite State Electric has filed a conservation plan with the PUC, and this is likely the same as that required in Massachusetts. Currently, only electric utilities are included in evaluation plans; however, the 
staff intends to recommend that gas utilities in New Hampshire be required to prepare DSM program evaluation plans.

Technical methods to determine conservation achievement and comparison of measured data to engineering estimates are of most interest to PUC staff involved in DSM M\&E efforts. Additionally, the useful life of a DSM measure, persistence of energy savings, and firstyear savings would be the top priorities in a review of any DSM program evaluation study. Utilities in New Hampshire currently use a variety of techniques in preparing DSM impact evaluation. The most favored by regulators is end-use monitoring; the staff wants to see more of it. Utilities use billing data analysis, but not always satisfactorily. Additionally, utilities use engineering estimates or calculations and hybrid methods. Savings calculated using data from other jurisdictions are reluctantly accepted by the staff, and savings estimates from other jurisdictions have been proposed but not yet done. The staff has proposed technology transferability analysis (such as the transfer of gas end-use data across jurisdictions).

It is too early to judge the quality and thoroughness of evaluation of DSM programs to date. Evaluation studies that have improved the quality of evaluation results include the monitoring of temperature-sensitive winterinterruptible load. Utility $R \& D$ to solve impact-evaluation problems is encouraged in New Hampshire. For example, a utility was able to do research on development of a database on end-uses without metering the interruptible load.

It is too early in the development of evaluation to project improvements.

Contact: Ms. Janet Besser

Utility Analyst

New Hampshire PSC

(603) 271-2431

\section{New Jersey}

The New Jersey BPU does not currently require impact evaluation. It is part of the usual and customary review of DSM program cost/benefit analysis during an electric utility rate case. Proposed regulations would require energy and capacity savings measurement. A ruling is also expected on incentives. The Conservation Incentives Rulemaking (NJ AC 14:12) is recorded in the May 6, 1991, New Jersey Register. Incentives will be based on "measured savings" for both electric and gas utilities.

Impact evaluations are recommended for all full-scale electric programs but not for energy audits or pilot DSM programs. The Conservation Incentives Rulemaking will place energy audit and customer information programs in the category of core programs. Evaluation is recommended for all full-scale and pilot gas DSM programs.

The BPU staff does not advise utilities on the best methods for performing impact evaluations unless a request is made by the utility. The new incentive rulemaking would give regulators the authority to approve DSM impact-evaluation plans by utilities. No evaluation plans have been submitted. The proposed rules apply to gas and electric utilities equally, with the exception that the BPU is asking only for pilot DSM programs for electric utilities but full-scale and pilot programs for natural-gas utilities. DSM impact-evaluation issues that the BPU staff is most interested in examining as part of an M\&E effort are technical methods to determine conservation achievement, the length or timing of metering periods, and accuracy of results. The proposed regulations do not address evaluation techniques.

Parameters of a DSM program evaluation are likely to include the useful life, persistence, and first-year savings of the DSM measure; the "snapback" effect; and load-shape changes. The staff indicated that it is not involved in this level of evaluation; however, all of these issues are expected to be important to the $M \& E$ effort. Techniques used by utilities and consid- 
ered satisfactory by regulators include billingdata analysis, engineering estimates, statistical methods, end-use monitoring, case studies of technology assessments, hybrid methods, and savings estimates from other jurisdictions. The proposed rules include provisions for measuredsavings documentation.

Commercial electric DSM programs have been found to be easier to meter, and therefore to evaluate, than residential programs. Most difficult to measure for energy savings are residential retrofits and air-conditioning rebates. The latter program has raised a debate on the issue of free riders.

Regulators in New Jersey are not satisfied with the quality and thoroughness of evaluation of DSM programs to date. Staff commented that "evaluation is only getting better." The recent first round of competitive bidding raised the state of the art for evaluation. Utilities held bidders to a rigorous level of accountability. BPU staff intends to apply these same standards to the utilities' DSM programs. Utilities have been encouraged to invest in $R \& D$ to solve impact-evaluation problems as a result of the heavy emphasis on program M\&E.

\section{Contacts: Mr. Michael Ambrosio \\ Mr. Anthony Polomski \\ New Jersey BPU \\ (201) 648-2129}

\section{New York}

The New York PSC requires both process and impact evaluation plans of DSM programs when the DSM program plans are submitted to the PSC for approval. Electric utilities submit budgets, conservation targets, and evaluation plans for each program. Incentives for net resource savings are awarded annually through the fuel adjustment charges to electric utilities. Incentives are available to all electric utilities.

Impact evaluations are required for all fullscale and pilot DSM programs. Information is required on energy audit and customer information programs, and with more focus on full-scale programs than on pilots. Since 1991, the PSC has asked utilities to promote DSM programs for commercial and industrial HVAC systems, high-efficiency lighting and curtailable-load programs, and residential energy audit programs. Additionally, the PSC has asked that utilities increase their investment in DSM from $\$ 140$ million to $\$ 190$ million.

The PSC has prepared guideline objectives of the DSM evaluation aspect of their directions on filing conservation plans. Regulators in New York have the authority to approve DSM impact evaluation plans by utilities. All electric utilities in New York have had DSM program plans approved. Approval is considered a green light to go ahead with implementation, but programs are still open to PSC staff recommendations and changes.

Gas and electric utilities are treated somewhat differently in New York in that the gas DSM program is less vigorous than the electric program. One result of an evaluation scoping study sponsored by the PSC and New York State Energy Research and Development Authority in 1990 is a permanent Program Evaluation Task Force and Advisory Group (PETA), which meets quarterly. The group hopes to develop clear guidelines for program evaluation rather than a more rigid set of requirements.

DSM impact-evaluation issues of most interest to staff involved in M\&E efforts include methods to determine conservation achievement; sampling techniques; experimental design, such as control-group studies; and accuracy of results. Length and timing of metering periods and support for improved marginal cost calculations for natural gas were less of a priority. The staff indicated the highest level of interest in persistence of energy savings and first-year savings. Load-shape changes were noted as likely to become more important in the future. "Snapback" effect, although controversial, appeared least interesting as part of an M\&E effort.

A variety of techniques are used by utilities and considered satisfactory by regulators in 
preparing a DSM impact evaluation. Billingdata analyses are considered whenever feasible. Engineering estimates or calculations are used but are not satisfactory to the PSC staff when used as the sole source of the evaluation. Hybrid applications, using statistical and engineering procedures, are often used. End-use monitoring is used extensively for capacityoriented direct-load applications. Savings calculated using data from other jurisdictions have been used slightly but are generally not accepted by PSC staff. Only one measure, residential compact fluorescent light bulbs, has been found to be particularly difficult to measure for energy savings.

PSC staff is not satisfied with the quality and thoroughness of evaluation of DSM programs to date. This is primarily because there has been very little of it yet. The PETA has been set up to address this area. Improvements in DSM program evaluation that have improved the quality of results are represented in the evaluation of curtailable direct-load programs. These programs are easily evaluated because it is easy to get accurate information. The staff is still working on better evaluation of free riders.

More encouragement of utility $R \& D$ to solve impact-evaluation problems is expected from the PETA. Most energy conservation $R \& D$ is now done through a subcommittee of the New York State Power Pool, and the Empire State Energy Research Corporation Staff would like to see evaluation methods improved by getting a better handle on commercial and industrial conservation programs. The staff believes that evaluation needs to be more open and more credible to the public.

$\begin{array}{ll}\text { Contact: } & \begin{array}{l}\text { Mr. Martin Cummings } \\ \text { Project Director for }\end{array} \\ & \text { Program Evaluatiun } \\ & \text { New York PSC } \\ & \text { (518) } 474-5365\end{array}$

\section{North Carolina}

There are no specific guidelines or requirements by the North Carolina Utilities Commission (NCUC) for the impact evaluation of DSM programs to measure conservation achievement. No incentives 'or conservation achievement are currently available to utilities However, the staff believes incentives and rigorous evaluation will be linked in the future. The NCUC recommends that utilities prepare an evaluation of all electric full-scale and pilot programs (to the extent appropriate). The NCUC does not advise utilities on the best methods for performing impact evaluations. Regulators have the authority to approve DSM impact evaluation plans by utilities but have not approved any utility plans to date. There are no naturalgas LCP or DSM programs submitted to the NCUC to date.

The DSM impact-evaluation issues of most interest to NCUC staff as part of an M\&E effort are technical methods to determine conservation achievement and accuracy of results (level of confidence). Other areas of interest include the useful life and persistence of energy savings, especially in high-efficiency lighting measures, and load-shape changes. Techniques used and considered most satisfactory by regulators in preparing a DSM evaluation are enduse monitoring ("wholeheartedly endorsed") and billing-daia analysis. Engineering estimates or calculations (includirig simulation models) are also used and considered satisfactory, provided they are maintained with timely updates. Utilities also use case studies of technology assessments and hybrid methods. Savings estimates from other jurisdictions may be used for new programs only but are not considered transferable to North Carolina.

One DSM measure cited as particularly difficult to measure for energy savings is residential compact fluorescent light bulbs. Utilities in North Carolina argue against installing these light bulbs because savings are so hard to distinguish from other end-uses of electricity. Electric utilities have been slow to adopt efficiency programs and have been concentrating on 
peak-shaving measures. Regulators are not satisfied with the quality and thoroughness of the evaluation of DSM programs to date. The NCUC has instructed utilities to improve their evaluation methods and to report on their methods on a regular basis starting in November 1990 .

There are no NCUC directives to encourage the utilities to invest in R\&D to solve impactevaluation problems. The staff would like to see improvements in technical methods, accuracy, and accountability. However, the current staff level at the NCUC is very small, and they do not expect to be able to be very active in DSM program evaluation.

$\begin{array}{ll}\text { Contact: } & \text { Mr. James McLawhorn } \\ & \text { NCUC } \\ & (919) 733-2267\end{array}$

\section{Oregon}

The Oregon PUC requires that DSM plans be submitted on a case-by-case basis. A current rate case (UE-79) includes incentive program planning with biennial DSM program plans that include evaluation using engineering estimates and verification. Any incentive payment for conservation would be tied to impact evaluation.

Impact evaluations are recommended, but not required, for energy audit and customer information programs. Impact evaluations of all full-scale and pilot DSM programs for both electric and gas utilities are recommended and may be implemented this year. The staff prefers a consistent evaluation procedure for both electric and gas DSM programs.

PUC staff does not advise utilities on the best methods for performing DSM impact evaluations. In practice, they often rely on the expertise of the utility evaluators. The staff understands this to be a developing field. Guidelines on DSM program goals are available to staff and utilities. Regulators in Oregon have the authority to approve DSM impact evaluation plans by utilities. Several utilities are scheduled for plan submission this year. To date, only Portland General Electric has submitted a draft Ver.fication Plan for a limited number of programs. Gas and electric utilities are not treated differently in terms of evaluation requirements, but there is a difference in expectations. Gas utilities are described as being about 18 months behind electric utilities in terms of DSM program development.

PUC staff involved in DSM impact-evaluation issues are most interested in addressing all areas of evaluation. Highest on the list is accuracy of results (level of confidence), followed by sampling techniques and experimental designs (such as control-group studies). The length and timing of metering periods was also interesting to the staff. Additionally, the staff is interested in the useful life of the DSM measure and in first-year savings. Load-shape changes have not been addressed by utilities or staf. Currently, companies want to use PRISM to evaluate DSM programs. The staff does not believe that adjusted models alone can supply sufficient data on free riders. The staff prefers the use of control groups.

Techniques used and considered satisfactory by utilities in preparing a DSM impact evaluation plan include billing-data analysis, engineering estimates or calculations, case studies of technology assessments, and hybrid methods. Enduse monitoring has been used in pilot programs for more accurate sample data. The staff wants to see more of this, particularly in commercial and industrial applications. Savings estimates from other jurisdictions are acceptable in lieu of more expensive studies, but they must be modified as actual data becomes available. Also, amenity issues (such as the air-conditioning component of heat pumps and increased comfort levels associated with less cost-effective measures such as storm windows) are not seen as directly related to impact evaluation but may be part of the screening criteria in DSM measure selection.

The staff is not satisfied with the quality and thoroughness of evaluation of DSM programs to date. Utilities are still marketing their pro- 
grams. Cost inputs to DSM programs are often not well supported. The staff would like to move evaluation effort to a more sophisticated level and develop a consistent evaluation framework.

The PUC staff generally encourages utility $R \& D$ to solve impact-evaluation problems, but the staff is not supportive of high-cost, longterm studies. Improvements in evaluation are difficult to project this early in the process. Utilities should integrate evaluation resources with in-house program issues. Evaluation is becoming a stronger issue.

Contact: Ms. Connie Kolter

Senior Economic Analyst

Oregon PUC

(503) 378-6636

\section{Texas}

The Texas PUC requires that electric utilities report on the number of participants in a DSM study as well as on the impact of the program. To date, the state of the art is engineering estimates. Incentives for conservation achievement are awarded through the rate of return, not in a separate payment to the utility. Evaluation methods where incentives are being considered are not believed to be more rigorous. The impact evaluation of energy audits and customer information programs is not recommended by the PUC. The PUC does recommend impact evaluations for all full-scale electric-DSM programs. Pilot programs are evaluated on a case-by-case basis. Utilities are generally asked to provide the best information available.

The PUC has not issued specific guidelines on the best methods for performing impact evaluations. However, utility and PUC staff usually discuss the best approach to program development and evaluation after a final order. Regulators in Texas do not have the authority to approve DSM impact evaluation plans by utilities. Utilities submit conservation plans every two years, but these are not subject to approval by the PUC. Rather, the PUC will pro- vide instruction to the utility on any changes to its plan during the next rate case proceeding. The Texas PUC does not regulate natural-gas distribution companies in Texas. That is covered by the Texas Railroad Commission. There is currently no activity in gas DSM.

Impact-evaluation issues of most interest to staff as part of an M\&E effort are sampling techniques; technical methods to determine conservation achievement; experimental design, such as control-group studies; length and timing of metering period; and accuracy of results. Additionally, the staff indicated the importance of the following parameters of an impact evaluation study: useful life, persistence, firstyear energy saving of a DSM measure, the "snapback" effect, and load-shape changes. Utilities in Texas use a variety of techniques in preparing an impact evaluation; those techniques are considered satisfactory by regulators. Billing-data analysis is used in a few cases, as are engineering estimates. Use of statistical methods, such as CDA, is rare. End-use monitoring is used by a few utilities and is strongly encouraged by staff. The PUC staff generally rejects the use of savings estimates from other jurisdictions; they are used only if no better numbers are available. Currently, about $80 \%$ of all data used in impact evaluations is derived from engineering estimates.

PUC staff is not satisfied with the quality and thoroughness of evaluation of DSM programs to date. Utilities seem to be reluctant to invest in DSM programs. Texas Utilities Electric Co. is cited as having the most thorough program. It currently has 14 DSM programs, including loadshifting and HVAC models. The quality of evaluation results has been improved with the new filing format for energy-efficiency plans. The new format has resulted in some utilities' calculating more realistic estimates of load impact for 36 periods per year. This is also expected to allow more time for discussion and development of impact evaluation plans.

$\begin{array}{ll}\text { Contact: } & \text { Mr. Nathan Treadway } \\ & \text { Texas PUC } \\ & (512) 458-0100\end{array}$




\section{Vermont}

The Vermont Public Service Board (PSB) has not issued prescriptive instruction on DSM program evaluation in rate cases or orders. Central Vermont Public Service Co. is expected to file its first LCP in six months; Green Mountain Power's LCP is due this spring. PSB staff expects some level of evaluation requirement in the near future, but it is not known what this will include. Currently, impact evaluations are recommended for energy audits and all fullscale and pilot DSM programs for both gas and electric utilities.

The PSB has issued guidelines on evaluation objectives, which are included in the LCI orders. Regulators in Vermont have the authority to approve DSM impact evaluation plans by utilities, but none has been approved to date. Gas and electric utilities are not treated differently in terms of evaluation requirements or expectations.

A number of DSM impact-evaluation issues have been under discussion as part of planning an M\&E effort. The most interesting to staff is statistical techniques to sample small populations. The staff is also interested in technical methods to determine conservation achievement, length and timing of metering periods, accuracy of results, and support for improved marginal cost calculations for natural gas. The most interesting parameters of a DSM M\&E effort are reported to be useful life of the DSM measure, persistence of energy savings, and load-shape changes.

Techniques used by utilities in preparing a DSM impact evaluation are limited to billing-data analysis and engineering estimates or calculations. The staff considers these techniques to be in the very early stages in Vermont. To date, utilities have not invested in end-use monitoring because it is judged to be too expensive. Utilities may be using savings estimates from other jurisdictions, but the staff has not made a judgment on this yet.
The staff believes that it is too early to judge the quality and thoroughness of evaluation of DSM programs to date. There has not been a meaningful level of documentation or evaluation plan prepared. The PSB staff intends to encourage utilities to invest in R\&D to solve impact-evaluation problems.

The staff feels that it is too early to project desirable improvements in evaluation at this time. However, it would like to see measuredsavings data in evaluation of DSM programs.

Contact: Mr. Rick Weston

Economist

Vermont PSB

(802)828-2358

\section{Washington}

The Washington Utilities and Transportation Commission (UTC) has not formally required impact evaluations of DSM programs to date. Evaluation requirements are likely to be required after the UTC order in Docket No. UE901183T, on June 30, 1991. Currently, impact evaluations are recommended, but not required, for energy audit and customer information programs and for all full-scale DSM programs. No pilot DSM programs are currently in place. Evaluation is recommended for both gas and electric utilities, but gas is not active in DSM programs at this time.

Guidelines on objectives for performing DSM impact evaluations may be included in the June 30 order. Regulators in Washington have not yet established the authority to approve DSM impact evaluation plans by utilities.

The UTC staff is most interested in two issues as part of an M\&E effort: technical methods to determine conservation achievement and accuracy of results. Additionally, staff is interested in examining the useful life of a DSM measure, first-year energy savings, and load-shape changes. Techniques used by utilities in preparing a DSM impact evaluation are limited to engineering estimates, case studies of technology 
assessments, and savings estimates from other jurisdictions. The staff was not aware of any utility studies using billing-data analysis, statistical methods, or end-use monitoring. One DSM measure has been found particularly difficult to measure for energy savings: new commercial construction.

The staff is not satisfied with the quality and thoroughness of evaluation of DSM programs to date. The staff would like to see more time given (by UTC and utility) staff on evaluation issues. The UTC encourages utility R\&D to solve impact-evaluation problems. For example, UTC staff has testified that the UTC has encouraged conservation R\&D and would consider rate recovery for conservation research.

$\begin{array}{ll}\text { Contact: } & \text { Ms. Deborah Ross } \\ & \text { Policy Specialist } \\ & \text { Washington UTC } \\ & \text { (206) 586-1186 }\end{array}$

\section{Wisconsin}

The PSC of Wisconsin requires that evaluation plans be filed with DSM program plans. Impact evaluation is a high priority to the PSC, and it is sometimes included in utility DSM evaluation plans. In general, utilities are asked to show how much energy savings were achieved as a result of the DSM program. There are no incentive payments for conservation achievement in Wisconsin. The staff is not convinced of the viability of basing incentives strictly on measured energy savings.

Evaluation is required for all full-scale and pilot DSM programs for both gas and electric utilities. The staff believes that process evaluation can serve planning purposes as well as impact evaluation. The PSC staff has prepared guidelines on the objectives of impact evaluation. It believes that impact evaluation is experimental and not a traditional regulatory area.

Regulators in Wisconsin have the authority to approve DSM impact evaluation plans by util- ities. All major electric utilities have been ordered by the Commission to submit plans in rate cases. The staff then approves or recommends changes to the plan. Gas utilities are estimated to be about four years behind the electric utilities in evaluation-plan development. Gas and electric utilities are not treated differently in requirements; however, gas is recognized to be at an earlier stage of development. Electric utilities are seen to have bigger problems than gas utilities at this time. The staff compares DSM by Wisconsin utilities to DSM activity by utilities nationwide. Wisconsin Electric Power (WEPCO) is reported to be doing as much in impact evaluation as any utility in the country.

The PSC staff is interested in examining a number of issues as part of a DSM program M\&E effort. Staff is most interested in technical methods to determine conservation achievement; experimental design, such as controlgroup studies; and accuracy of results. The staff would like to see more detail in sample design. This is important for replicating, or transferring, one method to other utilities. The staff is now working on the free-rider evaluation issue and feels that it represents a major gap in overall cost-effectiveness evaluations. Another area of current consideration is commercial DSM program impact assessment. Among the parameters of an M\&E effort, the staff is most interested in load-shape changes, free riders in the first year of implementation, the useful life of the measure, and persistence in energy savings.

Utilities in Wisconsin use a variety of techniques in preparing a DSM impact evaluation. The most commonly used is billing-data analysis. Engineering estimates or calculations are used but not always to the satisfaction of the staff. Statistical methods, such as Conditional Demand Analysis, are beginning to be used by the utilities and look promising. The staff prefers before-and-after end-use metering using control groups. This is beginning to be used by utilities, and the high cost will be balanced with the need for the most accurate results. Case studies of technology assessment are used somewhat; the staff, however, would like to see more commercial applications. The staff en- 
courages the utilities to use hybrid methods in an effort to raise the level of evaluation. Savings estimates from other jurisdictions are not used. A few conservation measures have been found to be particularly difficult to measure for energy savings (such as commercial nonlighting measures). Utilities have tried Conditional Demand Analysis and short-term metering to solve this problem. It is very difficult to measure the individual effects of a group of residential weatherization measures used together. Commercial and industrial measures are difficult to measure because of the confounding effect of variables in business practices.

The staff is generally satisfied in many areas of DSM evaluation in terms of quality and thoroughness of results. However, the staff reports that it is reaching a contentious stage of discussion on the appropriate level of utility investment in DSM evaluation. The staff is asking the utilities to go beyond billing analysis and more into metering. There have been serious questions raised as to the value and relevance of measuring energy consumption at fine levels of detail.

Improvements in evaluation methods have improved results of measuring commercial lighting. Electric utilities are currently working on a study of residential appliance end-uses that is funded by corporations. They hope to set up a statewide tracking system for this project.

The PSC encourages utilities to invest in R\&D to solve impact-evaluation problems through the DSM program evaluation plans. Evaluation has been a primary focus of the Wisconsin Center for Demand Side Research, which is currently conducting a meta-evaluation of completed DSM program evaluation studies. The project will investigate possible trends in 40 to 50 program evaluations in methodology and results. The staff would like to see the following improvements in evaluation: more collaborative metering studies, more research on the transferability of evaluation results, more meta-analysis, more hybrid analysis, and more attention to commercial nonlighting measures. The staff questions how much investment is really needed to implement and evaluate DSM programs. The PSC is concerned that evaluators be objective. They should not be the same people who implement the DSM programs. And finally, the staff expressed a need for more DSM impact evaluators.

$\begin{array}{ll}\text { Contacts: } & \text { Mr. Ralph Prahl } \\ & \text { Coordinator of DSM } \\ & \text { Evaluation Research } \\ & \text { Mr. Paul Newman } \\ & \text { Assistant Administrator for } \\ & \text { Electric Policy } \\ & \text { PSC of Wisconsin } \\ & \text { (608) 267-5112 }\end{array}$



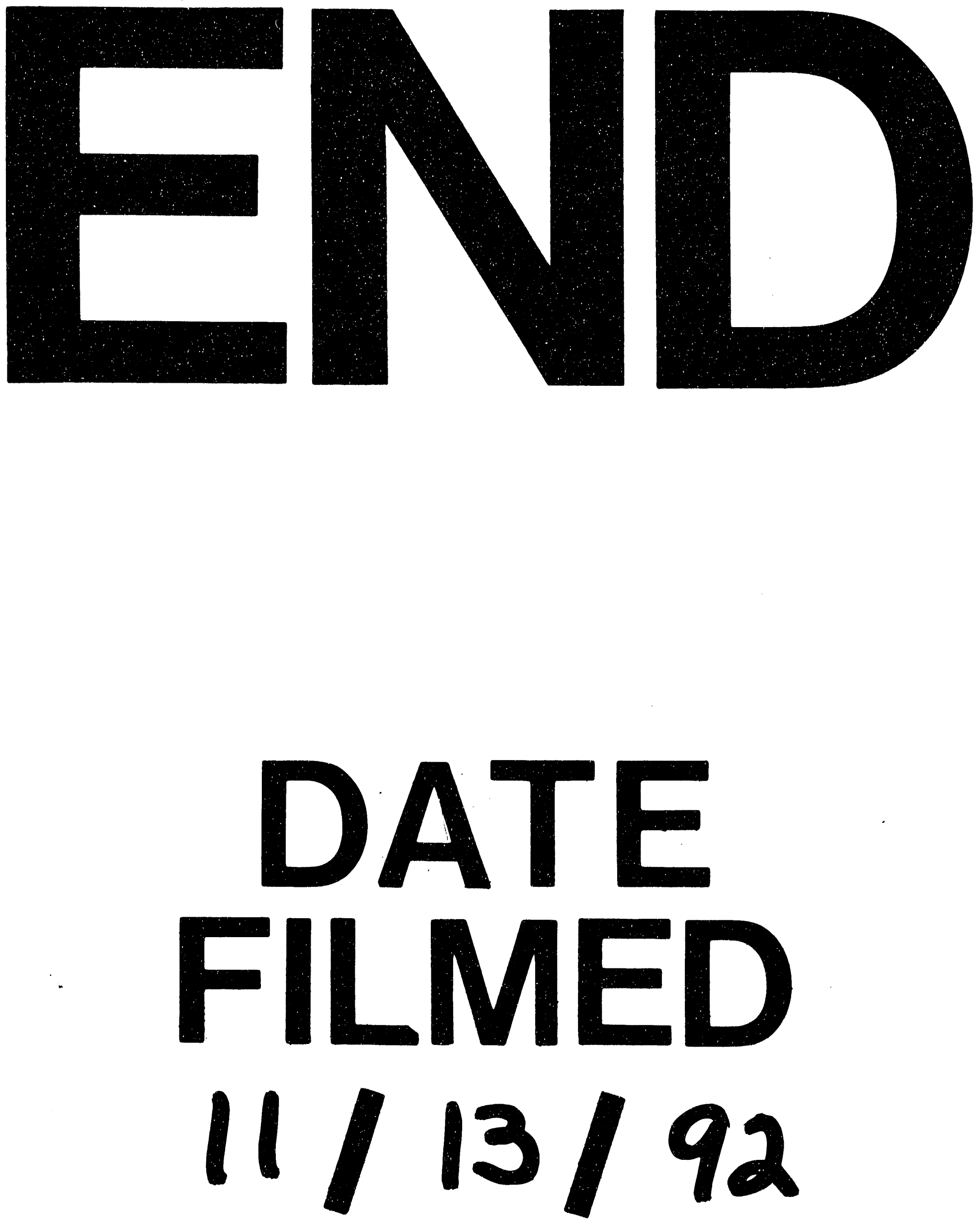

1 
